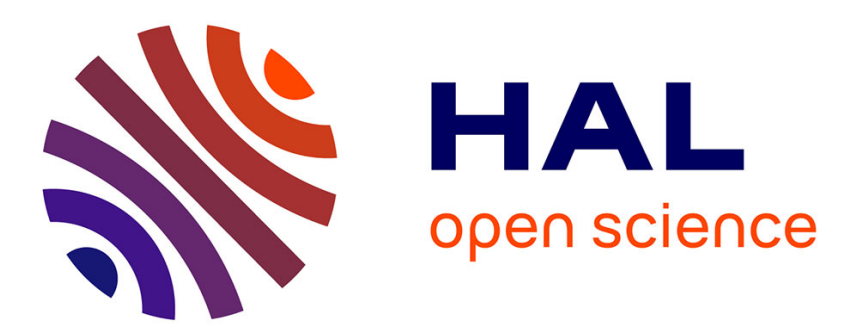

\title{
Global documentation of overlapping lobate deposits in Martian gullies
}

\author{
Rishitosh K Sinha, Dwijesh Ray, Tjalling de Haas, Susan Conway
}

\section{To cite this version:}

Rishitosh K Sinha, Dwijesh Ray, Tjalling de Haas, Susan Conway. Global documentation of overlapping lobate deposits in Martian gullies. Icarus, 2020, 352, pp.113979. 10.1016/j.icarus.2020.113979 . hal-02988354

\section{HAL Id: hal-02988354 \\ https://hal.science/hal-02988354}

Submitted on 4 Nov 2020

HAL is a multi-disciplinary open access archive for the deposit and dissemination of scientific research documents, whether they are published or not. The documents may come from teaching and research institutions in France or abroad, or from public or private research centers.
L'archive ouverte pluridisciplinaire HAL, est destinée au dépôt et à la diffusion de documents scientifiques de niveau recherche, publiés ou non, émanant des établissements d'enseignement et de recherche français ou étrangers, des laboratoires publics ou privés. 


\section{Global documentation of overlapping lobate deposits in Martian gullies}

Rishitosh K. Sinha ${ }^{*}, 1,2$, Dwijesh Ray ${ }^{1}$, Tjalling De Haas ${ }^{3}$, Susan Conway ${ }^{4}$

${ }^{1}$ Physical Research Laboratory, Ahmedabad 380009, Gujrat, India

${ }^{2}$ Indian Institute of Technology, Gandhinagar 382355, Gujarat, India

${ }^{3}$ Faculty of Geoscience, Universiteit Utrecht, Princetonlaan 8a, 3584 CB Utrecht, the Netherlands

${ }^{4}$ CNRS, UMR 6112 Laboratoire de Planétologie et Géodynamique, Université de Nantes, France

\section{*Corresponding Author}

Physical Research Laboratory

Ahmedabad -380 009

INDIA

Phone: +91-79 26314417

Fax: +91-79 26314407

E-mail address: rishitosh@prl.res.in

Running Title: Lobate deposits in gullies 


\begin{abstract}
Gullies on Mars are kilometre-scale sediment transport systems comprising an alcove, channel and debris apron. In some gullies lobate deposits have been observed, implying a debris-flow-like process, but uncertainty remains as to the importance of this process in the gully-population and whether lobate deposits are related to a specific context. Our study utilized the HiRISE image archive to document evidence of overlapping lobate deposits on gully-fan surfaces within craters emplaced between $30^{\circ}-75^{\circ}$ in both hemispheres. We have identified 26 craters in which lobate deposits occur in gullies, of which 6 were previously reported. This corresponds to $3.39 \%$ of the 765 gullied craters studied using 1004 HiRISE images. We show that gullies with lobate deposits (1) do not show any location preference, (2) are poleward-facing, (3) are found in craters with and without latitude dependent mantle (LDM) and/or glacier-like-forms, (4) are emplaced at slopes at the foot of the fans that range from $18-25^{\circ}$ in the northern and $7-19^{\circ}$ in the southern hemisphere, and (5) form in craters of all ages. From our observations, we infer that preservation of lobate deposits in gullies is the main factor leading to their relative paucity within the gully-population. Further, we observe morphological features associated with terrestrial wet-debris flows including: overlapping tongue-shaped terminal lobes, levees, channel backfilling, plug formation and avulsion. We have not observed any significant present-day changes in the morphology and topography of gullies and/or lobes. We conclude that a debris-flow-like process is likely responsible for the majority of sediment transport in gully-landforms.
\end{abstract}

\title{
1. Introduction
}

Morphological studies of Martian gullies have described them as steep slope drainage systems typically consisting an alcove, a channel and a depositional apron (Malin and Edgett, 
2000; Hartmann et al., 2003; Dickson and Head, 2009; Morgan et al., 2010; Reiss et al., 2011; Johnsson et al., 2014). Moreover, a number of additional morphologies have been reported to be associated with gully channels, such as lateral levees and lobate deposits. Many workers (e.g. Costard et al., 2002; Christensen, 2003; Reiss and Jaumann, 2003; Lanza et al., 2010; Levy et al., 2010a; Johnsson et al., 2014; De Haas et al., 2015a; Conway et al., 2015; Sinha et al., 2019) have studied such levees and lobate deposits and suggested that debris flows are likely to have formed gullies on Mars. The hypothesis that these debris flows were water bearing has emerged from (1) morphological comparison between lobate deposits found on Mars and Earth (Costard et al., 2002; Mangold et al., 2003; Conway et el., 2008; Lanza et al., 2010; Johnsson et al., 2014; Sinha et al., 2019), (2) detailed morphological study of lobate structures (Levy et al., 2010a), (3) correlation of Martian debris flow frequency with obliquity variations (De Haas et al., 2015b) and (4) sedimentological analysis of outcrop exposures in Martian gully-fans (De Haas et al., 2015a). However, the hypothesis of water bearing debris flows in gully formation does not comply with the fact that: (1) the Martian climate could not have supported substantial amounts of liquid water to flow on the surface during the Amazonian (Ingersoll 1970; Haberle et al. 2001; Hecht 2002; Richardson \& Mischna 2005; Sears \& Moore 2005), (2) gully-fans bearing debris flow like deposits have only been reported at a few sites (Levy et al., 2010a; Lanza et al., 2010; Johnsson et al., 2014; De Haas et al., 2015a) and (3) morphological features akin to wet debris flows have been reported to also form from $\mathrm{CO}_{2}$ frost sublimation (dry flows) (Dundas et al., 2010, 2012, 2015, 2019; De Haas et al., 2019a). Apart from wet debris flow formation, there are thus a number of alternative models for gully formation, which include: (1) fluvial (McEwen et al., 2007a; Head et al., 2008; Morgan et al., 2010; Reiss et al., 2011), (2) dry granular flows 
(Treiman, 2003; Bart, 2007; Pelletier et al., 2008), and (3) flows driven by $\mathrm{CO}_{2}$ frost sublimation (Hoffman, 2002; Ishii \& Sasaki, 200; Cedillo-Flores et al., 2011; Hansen et al., 2011).

Previous studies on morphological comparison of several hundred Martian gullies with their terrestrial counterparts led to the suggestion that most of the Martian gullies do not possess typical evidence of levees and lobate deposits (Reiss et al., 2009, 2011). Nevertheless, some of the Martian gullies that are consistent with morphologic evidence of levees and lobate deposits exhibit slope-area relationships similar to that for terrestrial water bearing debris flow channels (Lanza et al., 2010; Conway et al., 2011). De Haas et al. (2015a) pointed out that surficial observations may not be always useful in explaining the processes involved in gully formation, because the surface of gully-fans can be severely influenced by post depositional processes, which would hide surface expressions of lobate deposits. Furthermore, Mangold et al. (2010) suggested that sometimes it is impossible to unambiguously decide whether gully channels really lack levees. This is mainly because the levees in some cases may be too small $(<10 \mathrm{~cm})$ to be resolved in either Mars Orbiter Camera (MOC) or High Resolution Imaging Science Experiment (HiRISE) images.

Recent studies focused on temporal analysis of gullies with HiRISE images reported widespread contemporary activity in gullies which they interpret to be a result of gas released during $\mathrm{CO}_{2}$ frost sublimation (Diniega et al., 2010; Dundas et al., 2010, 2012, 2015, 2019; Pasquon et al., 2019a, 2019b). These studies have documented morphological evidence for new channel incision, apron deposition, terraces, leveés and lobate deposits, as a result of this ongoing gully activity. The previous assertion that well-developed leveéd channels formed in wet flows should not be evident in dry flows (Reiss et al., 2009; De Haas et al., 2015a) has now been refuted by reports of morphologic evidence of boulder-rich leveéd flows formed at the present day (Dundas et al., 2019). Accordingly, theoretical models involving flows triggered by $\mathrm{CO}_{2}$ gas 
sublimation in current Martian conditions have been proposed to explain ongoing gully activities (Cedillo-Flores et al., 2011; Pilorget and Forget, 2016). Together, these recent observations raise the question of whether liquid water was needed for the formation of Martian gullies, and whether the lobate deposits found in gullies stem from aqueous flows, dry flows, or both? A major step towards solving this question is unravelling the global distribution of lobate deposits in Martian gullies.

The Mars Reconnaissance Orbiter (MRO) High Resolution Imaging Science Experiment (HiRISE) (McEwen et al., 2007b) provides a high resolution $(\sim 25-50 \mathrm{~cm} /$ pixel) view of gully systems and has been the key dataset for the majority of the studies focused on morphological identification of levees and lobate deposits on gullies (Levy et al., 2010a; Lanza et al., 2010; Reiss et al., 2011; Johnsson et al., 2014; De Haas et al., 2015a; Sinha et al., 2019). We have conducted an extensive morphological study utilizing the available HiRISE images of the craters emplaced between $30^{\circ}-75^{\circ}$ in both the northern and southern hemispheres to document evidence of overlapping lobate deposits. Overlapping lobate deposits have been observed on the surface of gully-fans and at the base of crater walls in previous studies (Lanza et al., 2010; Levy et al., 2010a; Reiss et al., 2011; Johnsson et al., 2014; Conway et al., 2015; De Haas et al., 2015a, 2015b; Sinha et al., 2019), while being largely absent on many more gullies (e.g., Reiss et al., 2011; De Haas et al., 2015a).

The primary objective of this study is to investigate (1) whether morphologic evidence of overlapping lobate deposits is widespread and (2) infer if the presence of overlapping lobate deposits reflects a global climate signal or not. We further have the following sub-objectives: (a) What are the orientation preferences of crater wall slopes whereon lobate deposits are found? (b) What are the slope ranges of crater walls whereon the lobate deposits are emplaced? (c) Does age 
and morphology of the craters containing evidence of lobate deposits bear any influence on their formation and distribution? (d) Do the morphology and topography of gullies and lobate deposits show any changes that can be related to present-day activities?

The paper is structured as follows: We first describe the datasets and methods. Subsequently, we describe the geographic distribution of lobate deposits, detail their morphological characteristics, determine slope ranges and infer orientation preferences of crater walls whereon lobate deposits are emplaced. Thereafter, we describe the morphological characteristics of features observed within craters hosting lobate deposits and determine age relationships. Next, we describe the texture and post-depositional modification of lobate deposits, and search for morphological evidence of present-day activity in gullies associated with lobate deposits. Finally, we summarize the observations and provide a discussion on the possible origin of lobate deposits and their palaeoclimatic implications.

\section{Datasets and methods}

At a pixel scale ranging from $\sim 25-60 \mathrm{~cm}$, HiRISE images cover a $\sim 5-6 \mathrm{~km}$ wide swath (McEwen et al., 2018). In our survey, we investigate the HiRISE images located between $30^{\circ}-75^{\circ}$ in both hemispheres. We have chosen this latitudinal extent because previous studies have revealed that gullies are typically found in these regions (Heldmann and Mellon, 2004; Balme et al., 2006; Heldmann et al., 2007; Kneissl et al., 2010; Dickson et al., 2015; Harrison et al., 2015). The HiRISE images included in our investigation are located only on the slopes of crater walls. We focus on crater walls mainly because they provide us a unique opportunity to assess the influence of slope orientation on the distribution and development of lobate gully-forms (Kneissl et al., 2010). Another reason to exclusively focus on crater wall slopes is that this is the setting for the 
majority of gullies as shown by a number of previous studies (Balme et al., 2006; Heldmann et al., 2007; Kneissl et al., 2010; Harrison et al., 2015).

Images that contained overlapping coverage of the same portions of crater wall are rendered within ArcGIS to eradicate redundant observations. For a given crater, it is possible that there can be more than one HiRISE image covering different portions of the crater wall in which gullies could be present. Additionally, portions of crater wall for which there is no HiRISE image or the image is poorly illuminated may contain gullies. For instance, there are many larger diameter (e.g. $>50 \mathrm{~km}$ ) craters where HiRISE images do not cover the crater wall completely. If we find gullies in any of the HiRISE images covering the crater wall, we annotate that crater as 'crater with gullies in HiRISE'. For the craters in which we do not find gullies in the available HiRISE images, we annotate those craters as 'crater without gullies in HiRISE'.

For the identification of gullies in HiRISE images, we adopt the definition of a gully as proposed by Malin and Edgett (2000): "gullies are relatively small steep-sloped drainage systems typically consisting of an alcove, a channel and a depositional apron". Based on this definition, each HiRISE image was inspected for presence or absence of gullies using the Multi-Temporal Database of Planetary Image Data (MUTED) (Erkeling et al., 2016; Heyer et al., 2018), an online tool accessible at http://muted.wwu.de/. To identify overlapping lobate deposits, we based our search on morphologies resembling those already identified in the literature (e.g., Lanza et al., 2010, Reiss et al., 2011, Johnsson et al., 2014, De Haas et al., 2015a and Sinha et al., 2019) in which evidence for lobate deposits were reported inside 6 craters (Table 1). Of these 6 craters, 2 craters located in the northern hemisphere are reported by Sinha et al. (2019) and 1 crater each out of the remaining 4 craters in the southern hemisphere is reported by Lanza et al., 2010, Reiss et al., 2011, Johnsson et al., 2014, and De Haas et al., 2015a. By overlapping we mean that a 
lobe partly covers another formerly deposited lobe in the downslope direction. This distinct overlapping characteristic of lobes was previously recognized on a few fans (Lanza et al., 2010; Levy et al., 2010a; Reiss et al., 2011; Johnsson et al., 2014; De Haas et al., 2015a; Sinha et al., 2019). In the present study and in the previous reports, overlapping lobes are recognized by stacking of relatively small-sized individual lobes or laterally elongated lobes at the fan termini or at the fan surface. Images were examined at a map scale of 1:1000 using ESRI's (Environmental Systems Research Institute, Inc. Redlands, CA, USA) ArcMap 10.0.

Digital Terrain Models (DTMs) aligned on the Mars Orbiter Laser Altimeter (MOLA) topography were generated at a resolution of $\sim 18 \mathrm{~m} /$ pixel from CTX stereo imagery through the stereo-restitution pipeline of the Mars Information System application (MarsSI; emars.univlyon1.fr) (Lozac'h et al., 2015; Quantin-Nataf et al., 2018; Tao et al., 2018). Using ESRI's ArcGIS, we overlay the CTX images on the DTM to visually locate the crater wall slope surfaces where gullies and overlapping lobate deposits are found. Gully slopes were measured from alcove head to lobe termini along the main gully channel.

Using a combination of HiRISE and CTX images the orientation of crater wall slopes dominated by gullies accompanying overlapping lobate deposits is measured with respect to the geographic north (Heldmann et al., 2007). The absolute elevation of the source alcoves of gullies associated with overlapping lobate deposits was extracted from Mars Orbiter Laser Altimeter (MOLA) data (Smith et al., 2001).

The geological context in craters containing evidence of lobate deposits is categorized according to the morphology of the crater wall and floor. The interior of the craters is identified as glaciated or non-glaciated based on the morphologic evidence of flow features such as lobate 
debris apron (LDA) (Head et al., 2010) and concentric crater fill (CCF) (Levy et al., 2010b). In some cases, where we observed only a portion of the crater floor to be filled by viscous flow features emplaced from a particular face of crater wall, we categorized those craters as glaciated by small-scale LDAs (Sinha and Vijayan, 2017). Previous reports have revealed that these flow features are consistent with evidence of spatulate depressions at their margins (Head et al., 2008), display contrasting ridge structures or lineations on their surface and at the terminus (Arfstrom \& Hartmann, 2005), and tend to flow over/around obstacles (Baker et al., 2010; Sinha and Vijayan, 2017). These criteria have been used for the identification of flow features within craters in this study. We interpret the flow features to be associated with possible ice-related formation processes based on the evidence of brain-terrain texture (Noe Dobrea et al., 2007; Levy et al., 2010b), polygonal cracks of varying size and type (Levy et al., 2009) and ring-mold craters (Kress and Head, 2008). Together, based on the evidence of viscous flow features and arcuate ridges (Arfstrom \& Hartmann, 2005; Hubbard et al., 2011) within the craters, we classified them as glaciated or non-glaciated host craters. The identification of glaciated and non-glaciated craters was used for assessing the influence of glacial deposits on gullies associated with lobate deposits (De Haas et al., 2019b). We define the topography of the crater interior as undulated on the basis of hummocky units (e.g., cone and mesa-like features) and crater wall slump terraces on the crater wall and on the floor.

Morphological evidence of the latitude-dependent mantle (LDM; defined as a smooth, meters thick deposit of ice and dust) (e.g. Head et al., 2003) within the craters is recognized based on the appearance of gully alcoves, gully channels and crater walls. We use evidence of softened topography as the signature for possible drape of LDM deposits (Mustard et al., 2001; Kreslavsky \& Head, 2002). Furthermore, we categorize the crater walls, gully alcoves and 
channels to be consistent with evidence of LDM deposits on the basis of polygonized material and post-fracturing of the softened topography (Levy et al., 2009; Dickson et al., 2015; De Haas et al., 2019b). Polygonal cracks have further been surveyed on the craters' ejecta and outer crater walls to deduce the possible evidence for LDM emplacement. We also studied the downslope region of texturally disrupted bedrock exposures on the inner and outer walls of craters to find the evidence of LDM deposits (Conway et al., 2018).

CraterTools is used for measuring the crater size-frequency distribution over the ejecta blanket of craters containing lobate deposits (Kneissl et al., 2011; Michael et al., 2012). For those craters where ejecta is not apparent, appears modified or is superimposed by the ejecta of adjacent craters, we measure the crater size-frequency distribution over the small lobate debris apron (LDA) formed on the floor of the crater (Sinha and Vijayan, 2017). Craterstats 2.0 is used for plotting the counted craters and for determining the best-fit absolute model age. The crater count statistics are interpreted based on the production function by Ivanov (2001).

We classify the surface texture of the lobate deposits as either clast-rich or clast-poor (Johnsson et al., 2014). Evidence of recent rock fall activity in the form of boulder trails at the foot of crater wall slope is recognized as reflecting an active weathering environment within the crater (De Haas et al., 2013; Johnsson et al., 2014; Tesson et al., 2019).

\section{Observations and results}

\subsection{Geographic distribution}

In total, 988 craters in the northern hemisphere and 738 craters in the southern hemisphere are analysed using HiRISE images within the $30^{\circ}-75^{\circ}$ latitude range (Figure 1). In the northern hemisphere, we find morphologic evidence of gullies in 278 craters $(28.13 \%$ of total) covered by 
a total of 405 HiRISE images. In the southern hemisphere, gullies are found on the crater walls of 487 craters $(65.98 \%$ of total), covered by 599 HiRISE images. Within these 278 gullied craters in the northern hemisphere, morphological evidence of overlapping lobate deposit is newly found in 6 craters - referred to as 'craters hosting lobate deposits' from this point onwards (Table 1; Figure 1). Previously, 2 craters hosting lobate deposits were identified in the northern hemisphere by Sinha et al., 2019 (Table 1; Figure 1). Of the 487 gullied craters present in the southern hemisphere, we have newly found 14 craters hosting lobate deposits (Table 1) (Figure 1). In the southern hemisphere, previously 4 craters hosting lobate deposits were identified by Lanza et al. (2010), Reiss et al. (2011), Johnsson et al. (2014), and De Haas et al. (2015a) (Table 1; Figure 1). This results in a total of 26 craters in which lobate deposits occur in gullies.

We find that the craters hosting lobate deposits are not clustered in any particular region within either hemisphere. In the southern hemisphere, the craters hosting lobate deposits span a wide range of longitudes (Table 1), while the latitudinal distribution of craters hosting lobate deposits is confined between $\sim 33.0^{\circ}-46.0^{\circ} \mathrm{S}$ (Figure 1). The craters hosting lobate deposits in the northern hemisphere are found within $134.5^{\circ} \mathrm{W}$ to $26.5^{\circ} \mathrm{E}$ and $40.5^{\circ} \mathrm{N}$ to $53.7^{\circ} \mathrm{N}$ (Table 1; Figure 1). Overall, the craters hosting lobate deposits in the northern hemisphere have a slightly larger latitudinal range than the craters hosting lobate deposits in the southern hemisphere. We find that overlapping lobate deposits occur in craters with diameters ranging from $\sim 2-30 \mathrm{~km}$ and $\sim 3-36$ $\mathrm{km}$ in the northern and southern hemispheres, respectively (Table 1). The alcoves of gullies consistent with lobate deposits are found at elevations ranging from $\sim-3.9$ to $\sim 2.7 \mathrm{~km}$ in the northern hemisphere and $\sim 0.3$ to $\sim 5 \mathrm{~km}$ in the southern hemisphere (Table 1). 


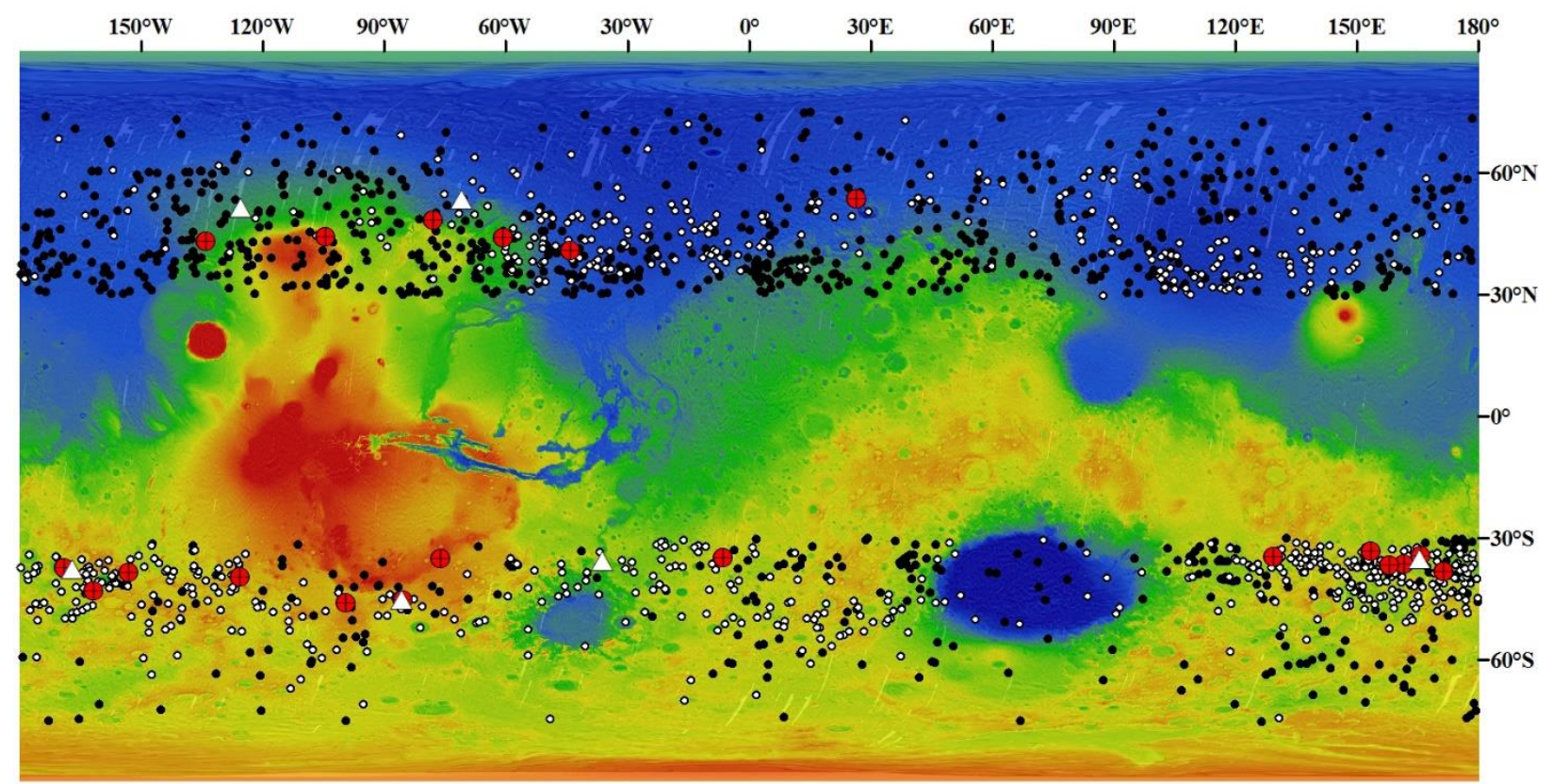

Figure 1. Distribution of overlapping lobate deposits in gullied craters between $30^{\circ}-75^{\circ} \mathrm{N}$ and $\mathrm{S}$ plotted over the Mars Orbiter Laser Altimeter (MOLA; red is high elevation and blue is low elevation) topographic data superposed on the Mars Odyssey THEMIS daytime thermal infrared global mosaic $(100 \mathrm{~m} /$ pixel). The colors of the symbols indicate: white circles-craters with gullies in HiRISE, black circles - craters without gullies in HiRISE, red circle with plus - gullied craters with overlapping lobate deposits, and white triangles - previously reported gullied craters with overlapping lobate deposits. Basemap image credit: MOLA/GSFC/USGS. 


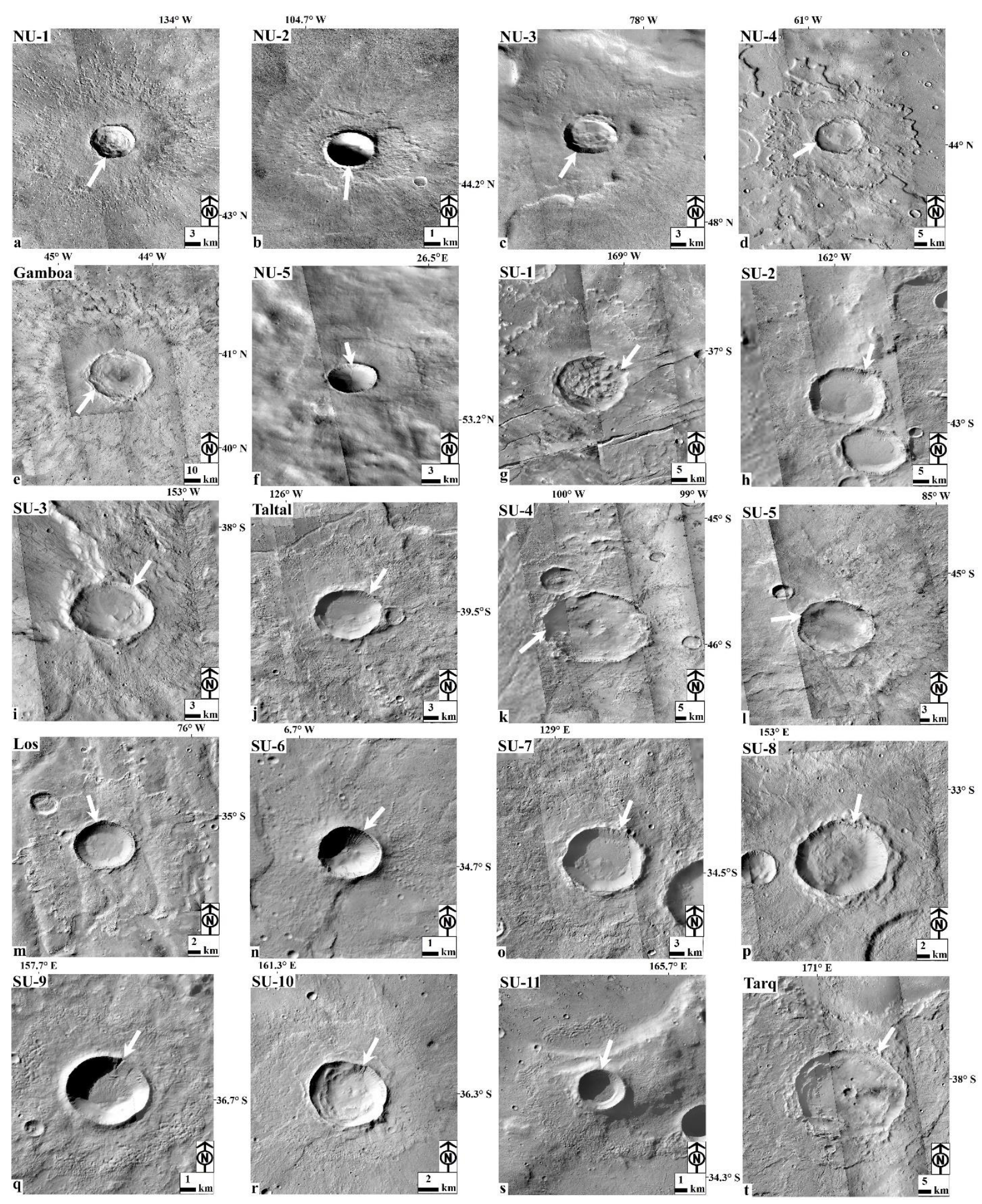

Figure 2. CTX mosaics of the 20 craters hosting lobate deposits in the northern and southern hemisphere. The arrow in each of these craters shows the location of the gully systems where we 
have identified overlapping lobate deposits. Detailed panels of the lobate deposits are shown in Figure 3. The CTX image Ids are given in Table 1. Image credit: NASA/JPL-Caltech/MSSS.

\subsection{Morphology of overlapping lobate deposits}

Figure 2 shows the 20 craters in which morphologic evidence for overlapping lobate deposits are newly found on gullies (Figure 3). The lobes typically have a convex-up tongueshape, and commonly display a straight to slightly sinuous flow pattern in plan view. In some instances lobes are connected to channels, which are often flanked by lateral levees (Figure 4a), while channels are not evidently connected to lobes in other instances, likely as a result of burial by subsequent events (Figure 4b). There can be series of terminal lobes stacked together, often regressively by backstepping (Figure $\mathbf{4 c}$, f), or laterally thereby forming broad deposit complexes (Figure 4g, h). Both these forms co-exist within most of the gullies hosting lobate deposits. Lobes generally form local areas of high relief (Figure $\mathbf{4} \mathbf{i}, \mathbf{j}$ ) that steer subsequent flow deposits towards topographically lower areas (Figure 4k-o). In a few examples, the fan surfaces adjacent to stacked lobes are rich in boulders (Figure 4p).

We often observe patterns of channel plugging, backstepping and avulsion, typical for the spatio temporal evolution of fans formed by lobate deposits (Figure 5) (De Haas et al., 2016, 2018, 2019c). Most notably, in Taltal, Los, SU-5, SU-7, SU-10, and NU-1 craters, channels that emplaced an elongated lobate deposit or that were blocked by a lobate deposit were completely buried as a result of channel backfilling by subsequent lobe emplacement, ultimately resulting in avulsion (Figure 5a-l). The channel and deposits are elongated when there was effective levee formation (e.g. in SU-4, NU-1) (Figure 5m, n), while the unchannelized flows formed short and 
wide deposits (e.g. in SU-6) (Figure 5o). These differences appear to be related to the grain size distribution in the lobes, where an absence of sufficient large particles inhibits levee formation and enhances lateral spreading. Such behaviour is common in terrestrial debris flows (De Haas et al., 2015c). 


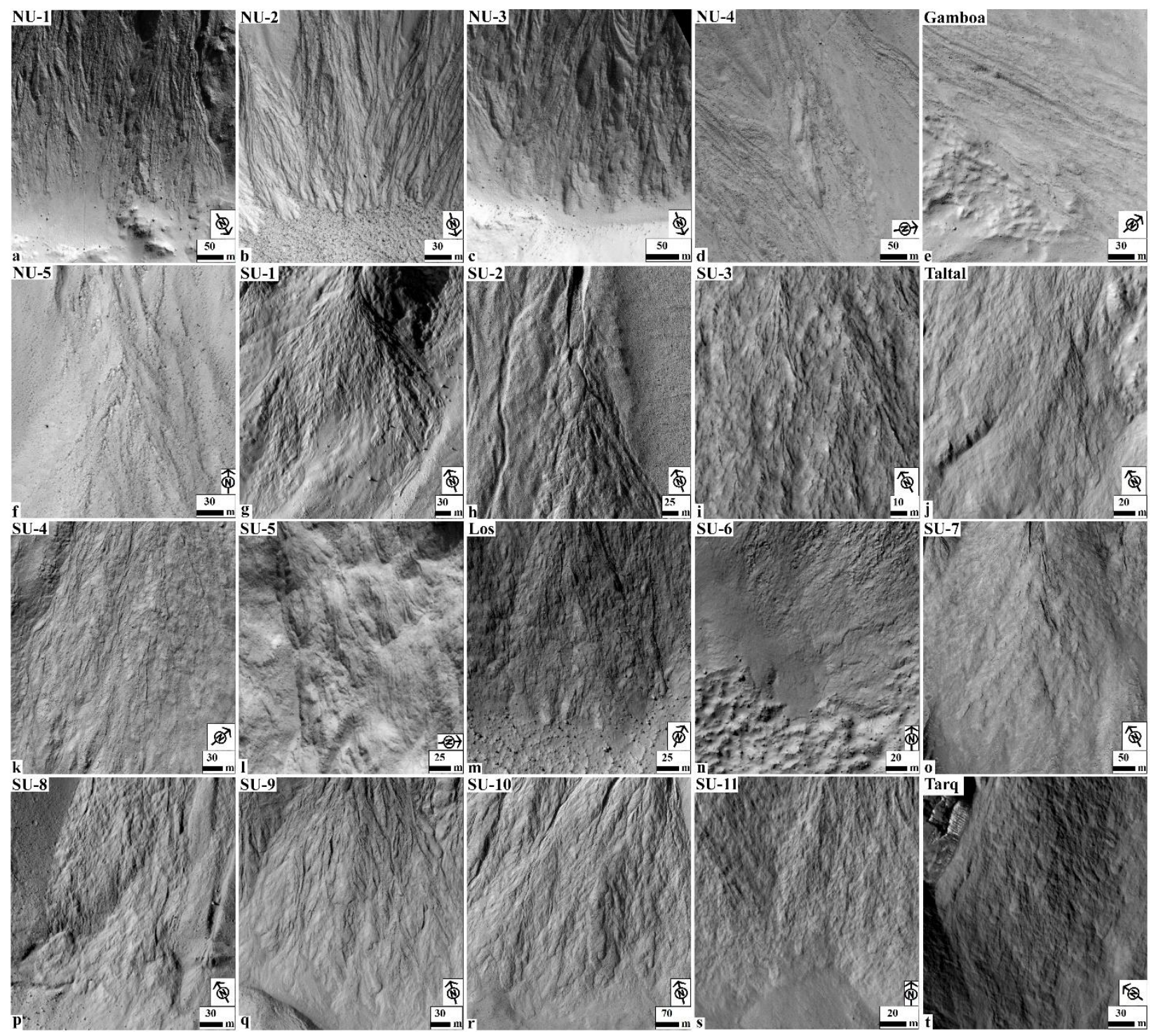

Figure 3. Morphology of overlapping lobate deposits. The location of these zoomed-in figures is represented by arrows in Figure 2. The HiRISE image Ids of corresponding craters are given in Table 1. Image credit: NASA/JPL-Caltech/University of Arizona. 


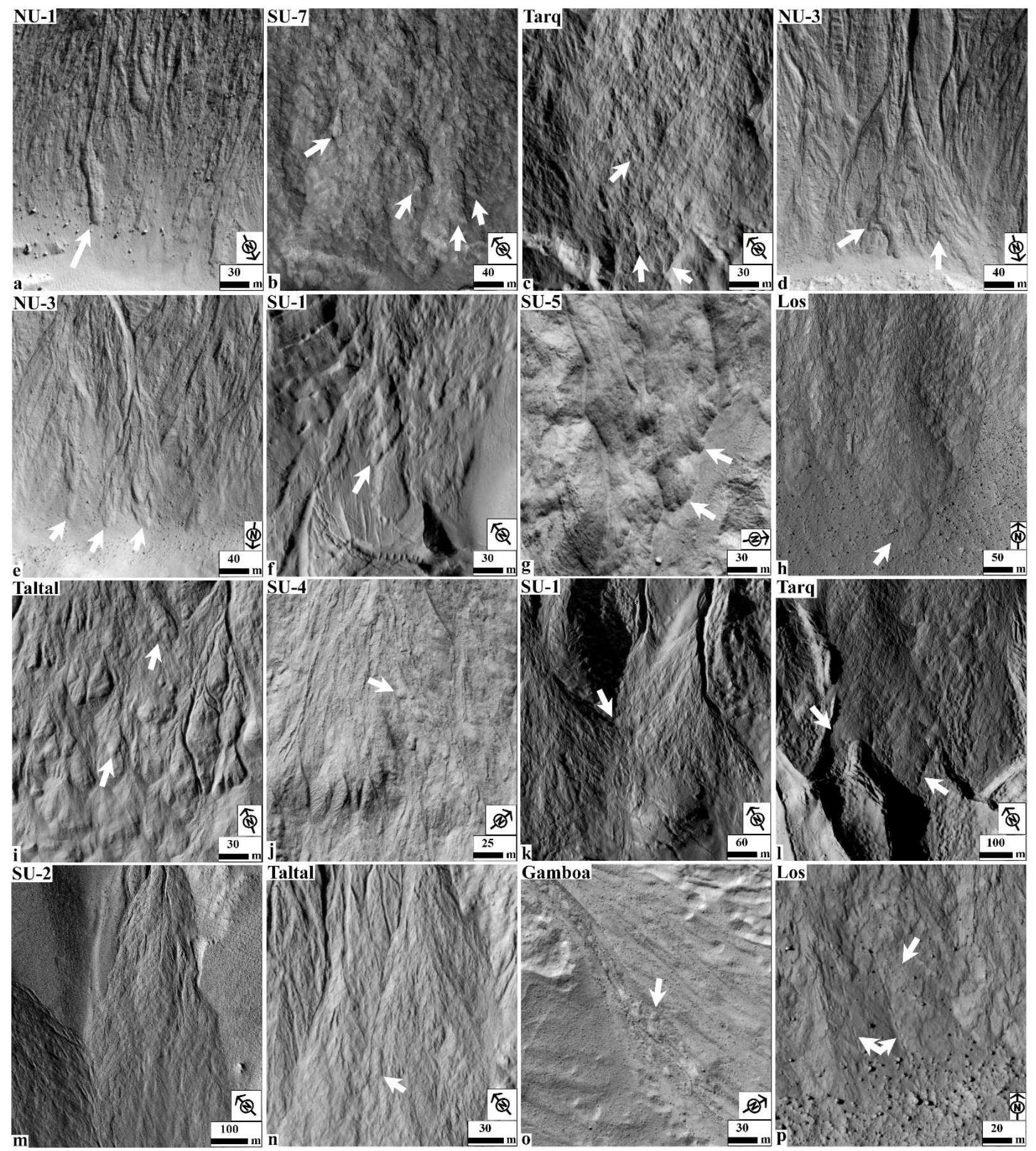

Figure 4. Examples of morphologies (shown by arrows) observed within the overlapping lobate

deposits. (a) Lobate deposit connected to a channel (HIRISE: ESP_046028_2235). (b) Channels associated with lobes are not evident (HIRISE: ESP_013870_1450). (c-d) Evidence for multiple lobes stacked together on a gully surface (HIRISE: ESP_036839_1420,ESP_028290_2285).(e-f) 
Successive emplacement of lobes (HIRISE: ESP_028290_2285, ESP_036324_1425). (g-h) Broad deposits formed from laterally accumulating lobes (HIRISE: ESP_047464_1345, ESP_020774_1445). (i-j) Relatively high relief of lobes in comparison to adjacent fan surface (HIRISE: ESP_016042_1400,ESP_030045_1340). (k) Orientation and emplacement of lobes constrained by the local relief of older deposits (HIRISE: ESP_036324_1425). (l) Emplacement of a lobe constrained by the topography of downslope features (HIRISE: ESP_036839_1420).(m) Complex stratigraphy of overlapping lobes and associated channels (HIRISE: PSP_007143_1370). (n-o) Channel superposition by lobes (HIRISE: PSP_007143_1370, ESP_036451_2210). (p) Boulder trails evident on the fan surface (HIRISE: ESP_020774_1445). Image credit: NASA/JPL-Caltech/University of Arizona. 


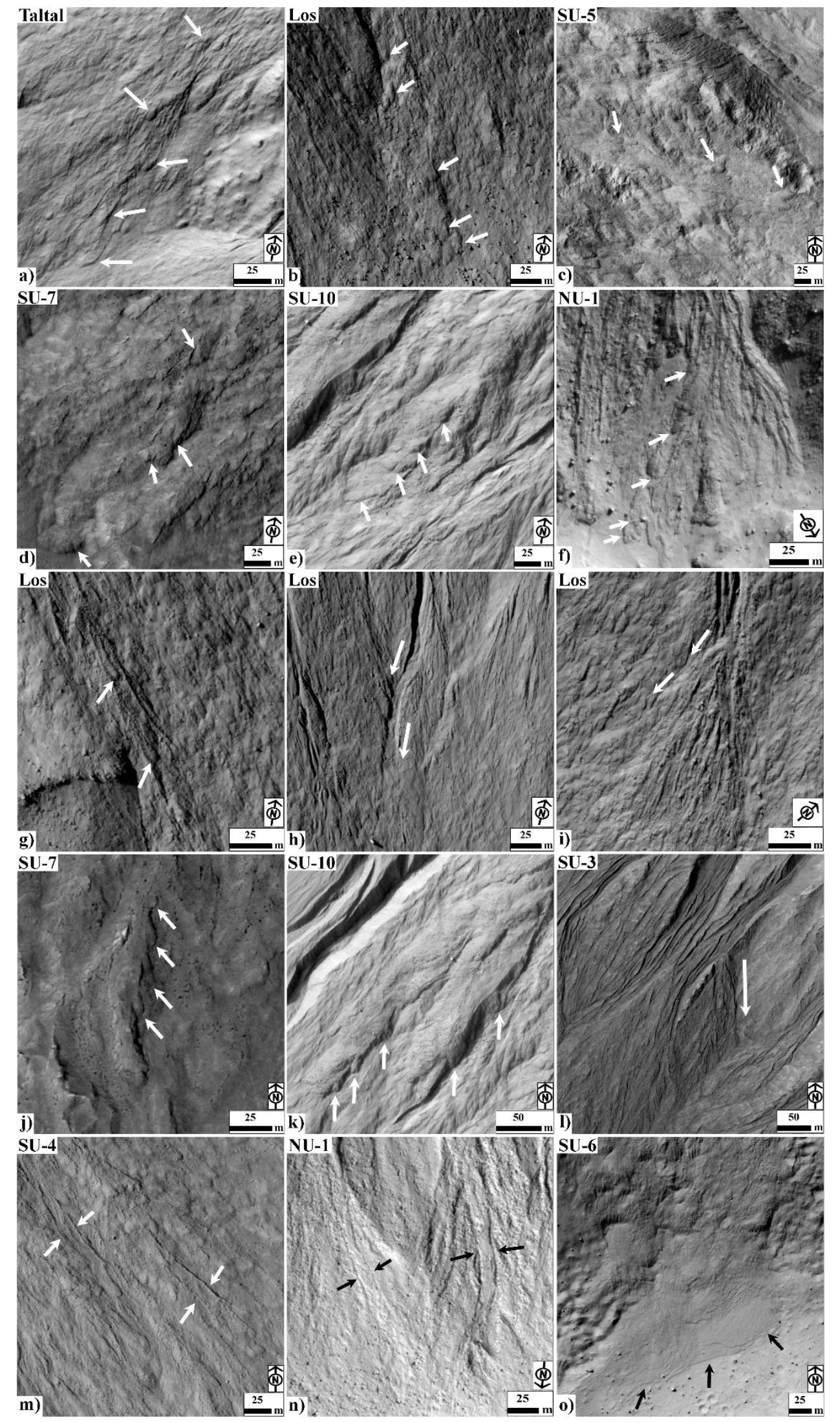

Figure 5. (a-f) Channel backfilling by backstepping of subsequent lobe deposits (HIRISE: 
ESP_016042_1400, HIRISE: ESP_020774_1445, ESP_047464_1345, ESP_013870_1450, ESP_028308_1435,ESP_046028_2235). (g) Channel plugs (HIRISE: ESP_020774_1445). (h) Avulsion leading to formation of new channel (HIRISE: ESP_020774_1445). (i-k) Examples of unchannelized avulsion (HIRISE: ESP_020774_1445, ESP_013870_1450, ESP_028308_1435). (l) Possible breach and overbank flow (HIRISE: ESP_038473_1415). (m-n) Levees formed in elongated channelized flows (HIRISE: ESP_030045_1340, ESP_046028_2235). (o) Short and wide unchannelized flow (HIRISE: PSP_007045_1450). Image credit: NASA/JPLCaltech/University of Arizona.

\subsection{Slope relationships}

Slope is estimated for gullies and lobate deposits within 16 of the 20 craters hosting lobate deposits (Table 1). For the remaining 4 craters (NU-3, NU-4, NU-5 and SU-9), CTX stereo imagery is not available (Table 1). In the northern hemisphere, slopes at the upper and middle portions of gullies associated with lobate deposits are between 22 and $39^{\circ}$, with an average slope of $32.5^{\circ}$. The slope of lobate deposits at the foot of the fans ranges from $18-25^{\circ}$, with an average slope value of $22.5^{\circ}$. In the southern hemisphere, slopes at the upper and middle portions of gullies associated with lobate deposits are on average $27.5^{\circ}$ and range between 14 and $40^{\circ}$. The slopes at the lobate deposits are between 7 and $19^{\circ}$, with an average slope value of $11.5^{\circ}$. As such, the slope values estimated for lobate deposits in the northern hemisphere are slightly higher in comparison to slopes at lobate deposits in the southern hemisphere.

\subsection{Orientation}


The gullies formed in the craters hosting lobate deposits in the southern hemisphere show a poleward-facing trend at latitudes within $30^{\circ}-40^{\circ} \mathrm{S}$ (Table 1). At latitudes $40^{\circ}-46^{\circ} \mathrm{S}$ gullies show both poleward-facing and equatorward-facing orientations; however, the dominant orientation preference is poleward-facing as the population of gullies on the pole-facing wall is relatively denser than that over the equator-facing wall. The lobate deposits associated with gullies in all the craters hosting lobate deposits has a dominant poleward-facing trend (Table 1). There are gullies with an equatorward-facing orientation on the walls of SU-2, SU-4 and SU-5 located at $40^{\circ}-46^{\circ} \mathrm{S}$, but these gullies do not host lobate deposits.

In the northern hemisphere, lobate deposits are evident on the equator-facing slopes only within NU-5 located at $\sim 53.61^{\circ} \mathrm{N}$ (Table 1). For the remaining 5 craters located between $40^{\circ}$ and $50^{\circ} \mathrm{N}$, the lobate deposits are found on poleward-facing slopes (Table 1). Within these craters gullies are found on both the poleward and equator facing slopes in NU-4, Gamboa and NU-5, while NU-1, NU-2 and NU-3 have gullies only on their poleward-facing slopes (Table 1).

\subsection{Association with glacial and LDM deposits}

In the northern hemisphere, none of the craters hosting lobate deposits have their interior filled with LDA/CCF (Table 1). This suggests that the gullies and lobate deposits formed in these craters are not associated with glacial deposits. This could explain the relatively high slopes of the gullies with lobate deposits in the northern hemisphere. Still, NU-1, NU-3, NU-4 and Gamboa are characterized by undulated crater floor topography possibly resulting from their hummocky interior and slump terraces over the crater wall and on the floor (Figure 2). These four craters have circular and elongated pits evident on their floor (e.g. Figure 6a). NU-3 and Gamboa are the only two craters with polygons on gully walls and alcoves. In NU-4, the polygons are distinctly mantled 
by dust hindering their identification. NU-3 also hosts polygonal cracks on its floor, which seem to have formed within material draped over the pre-existing surface (Figure 6b). In NU-3 and NU5 polygonized material is evident on the outer wall region outside the crater (e.g. Figure 6c). All the craters hosting lobate deposits in the northern hemisphere are dominated by numerous clasts/boulders over the gullied walls (e.g. Figure 6d). Fresh boulder trails are evident at the foot of walls of NU-1, NU-4 and Gamboa. NU-4 has also preserved dunes, ripples and transverse aeolian ridges (TARs) on its floor. 

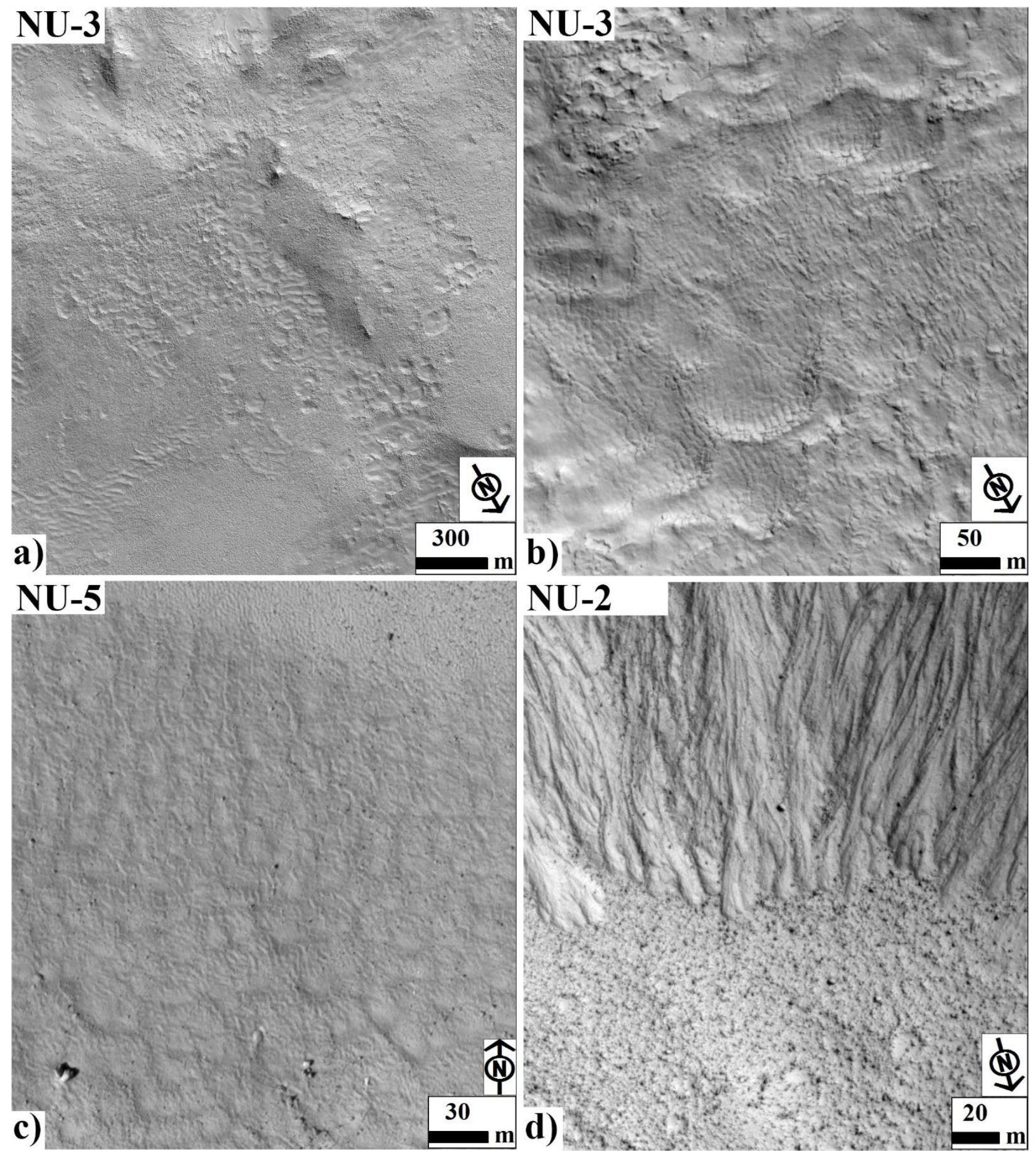

Figure 6. (a) Circular and elongated pits on the floor (HIRISE: ESP_028290_2285). (b) Polygon cracks on craterfloor(HIRISE: ESP_028290_2285). (c) Polygonal cracks in the outer wall region of a crater (HIRISE: ESP_036501_2340). (d) Boulders accumulated at the foot of the wall of a crater (HIRISE: ESP_043073_2245). Image credit: NASA/JPL-Caltech/University of Arizona. 
The softened appearance of the topography of the alcoves and gully-fan deposits in NU-1, NU-2, NU-3, NU-4 and NU-5 suggests that they are covered by LDM deposits (e.g. Figure 7a-c). The evidence of draped LDM deposits in the downslope of texturally disrupted bedrock on the inner wall is evident in Gamboa, as implied by the patterned ground in these deposits (Figure 7d).

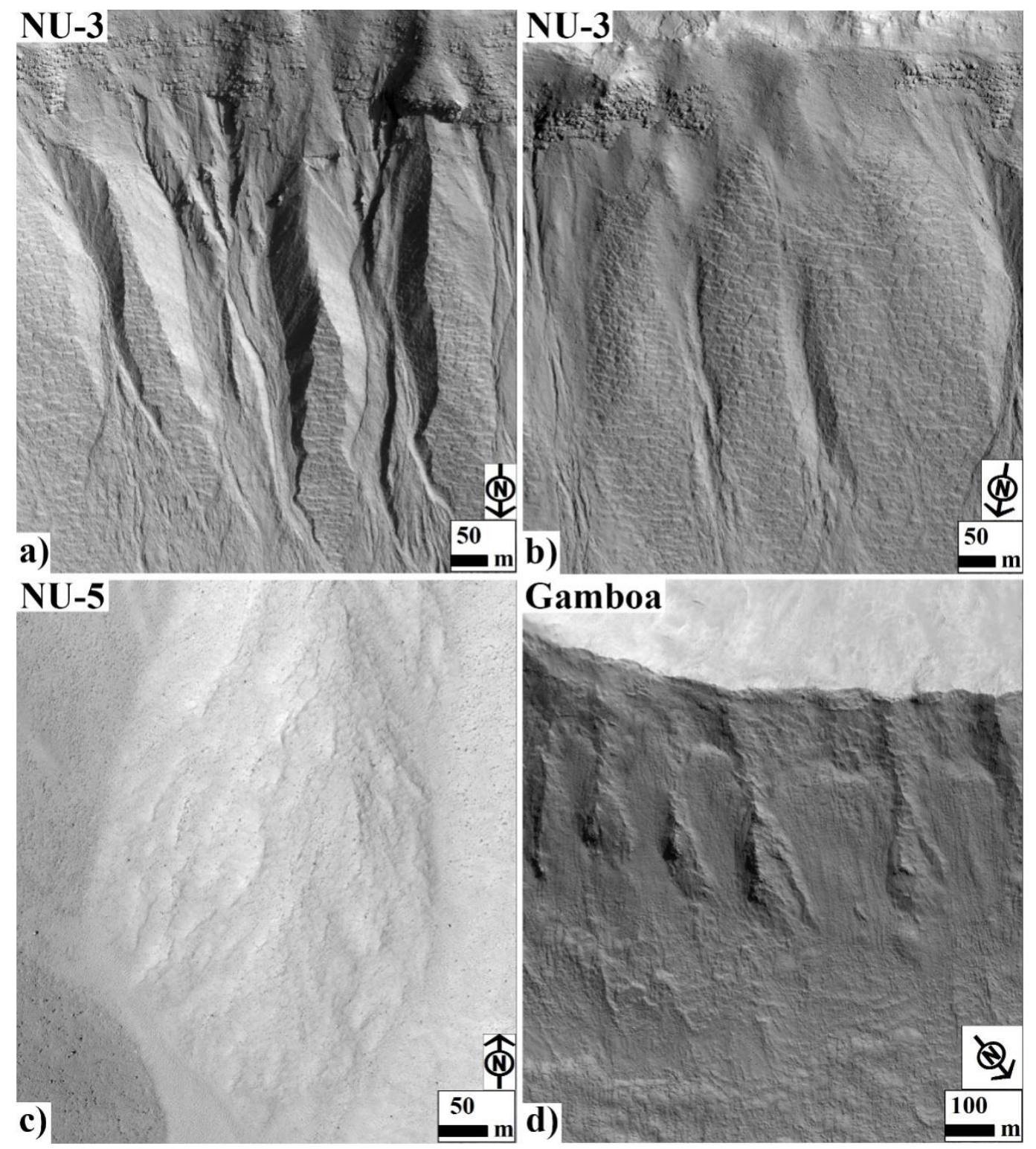

Figure 7. (a) Polygonized alcoves and gully walls (HIRISE: ESP_028290_2285). (b) Softened topography of the crater wall (HIRISE: ESP_028290_2285). (c) Softened topography of the gully 
fan (HIRISE: ESP_036501_2340). (d) Draped LDM deposits on the texturally disrupted wall of a crater (HIRISE: ESP_036451_2210). Image credit: NASA/JPL-Caltech/University of Arizona.

In the southern hemisphere, small-scale LDAs are emplaced from the pole-facing crater wall slopes of SU-2, SU-3, Taltal, SU-4, SU-5, SU-7, SU-9, SU-11 and Tarq (Figure 2). The surfaces of these small-scale LDAs are consistent with brain-terrain texture and spatulate depressions at the headwards margin of the LDAs (e.g. Figure 8a-c). Arcuate ridges are commonly observed in all the craters with glacial deposits (e.g. Figure 8d). In SU-1, Los, SU-6, SU-8 and SU-10 glacial deposits are absent. All walls of the craters with lobate deposits in the southern hemisphere are rich in clasts/boulders, suggesting an active weathering environment. Further, polygonized crater wall surfaces and gully alcoves are evident in SU-2, SU-3, Taltal, SU-4, SU-5, SU-6, SU-7, SU-9, SU-11 and Tarq (e.g. Figure 8e). Furthermore, these craters show softened topography resulting from LDM cover (e.g. Figure 8f). In SU-8 and SU-10, there is no evidence of polygonized material although softened crater wall topography and infilled alcoves are evident. Los is the only crater in the southern hemisphere with no evidence of LDM or glacial deposits. There is some evidence of fresh gullies in the mantled crater wall of SU-1 (Figure 8g) and beheaded gullies and fans in SU-5, SU-7 and SU-11 (e.g. Figure 8h). Crater wall slopes of SU-1 host gully-fan systems that shows superposing relationships with dunes/TARs in the interior of the crater (Figure 8i). 


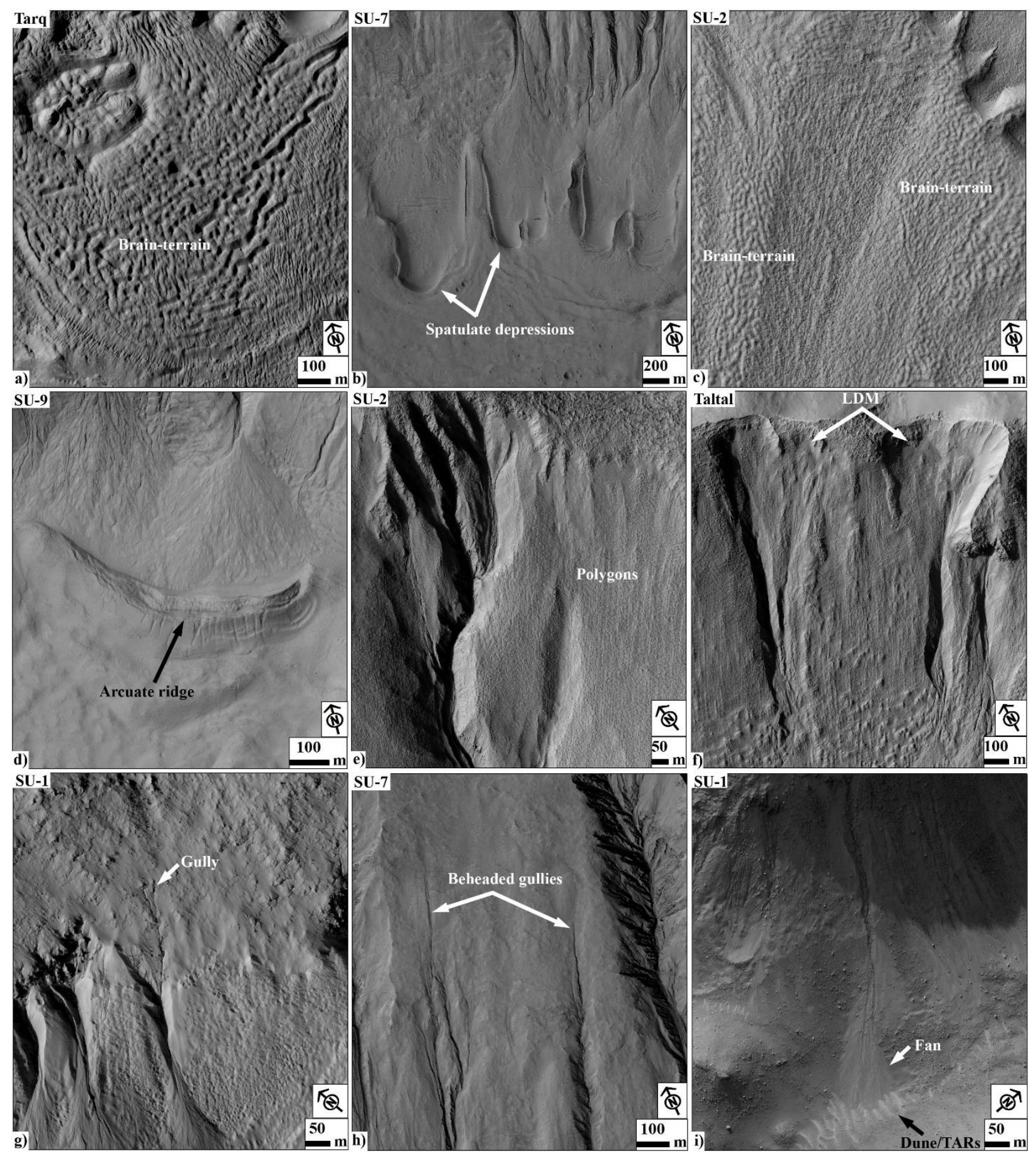

Figure 8. (a) LDA surface consistent with brain-terrain texture (HIRISE: ESP_036839_1420).(b)

LDA flow feature with spatulate depressions (arrow) (HIRISE: ESP_013870_1450). (c) CCF consistent with brain-terrain surface texture (HIRISE: PSP_007143_1370). (d) Arcuate ridge on 
the floor of a crater (arrow) (HIRISE: ESP_023640_1430). (e) Polygonal cracks on the wall of a crater (HIRISE: PSP_007143_1370). (f) LDM deposits draped over alcoves and gully walls (HIRISE: ESP_016042_1400). (g) Fresh gullies over the wall of a crater (arrow) (HIRISE: ESP_036324_1425). (h) Beheaded gullies on the wall of a crater (arrow) (HIRISE: ESP_013870_1450). (i) Gully fans superposed over dune/TARs (arrow) (HIRISE: ESP_036324_1425). Image credit: NASA/JPL-Caltech/University of Arizona.

\subsection{Age relationships}

We have estimated maximum ages of gully formation for 16 craters based on the crater size frequency distribution (CSFD) (Table 1). For SU-2, SU-7 and Tarq, CSFD measurements have been done on the small-scale LDA flow units on the crater floor, while for the remaining 13 craters CSFD measurements have been done on the craters' ejecta. For NU-1, SU-4, SU-6 and SU8, CSFD could not be performed because the ejecta was heavily mantled, the ejecta was not apparent, or the ejecta was mixed with ejecta of adjacent craters.

Lobate deposits are found in host craters of all ages (Figure 9). The host craters in the northern hemisphere have ages in the range of $\sim 1.6 \pm 0.2$ Ma to $\sim 270 \pm 60$ Ma (Table 1). In the southern hemisphere, the host craters range in age between $\sim 7.9 \pm 3$ Ma to $\sim 3.0 \pm 0.3 \mathrm{Ga}$ (Table 1). The glacial deposits emplaced over the floor of SU-2, SU-7 and Tarq yield an average best-fit age of $\sim 30 \mathrm{Ma}$ (Table 1). For these craters cross-cutting relations show that the lobate deposits formed in gullies are younger than the age of glacial deposits emplaced.

All the craters hosting lobate deposits in the northern hemisphere are found to be affected by LDM deposits and unaffected by LDA/CCF regardless of their age (Figure 9; Table 1). In the 
southern hemisphere Los is the only crater unaffected by LDM or glaciation (Figure 9), and it is also the youngest host crater $(\sim 7.9 \pm 3 \mathrm{Ma})$. The other craters hosting lobate deposits in the southern hemisphere are affected by LDM deposits and LDA/CCF, except for SU-10 which is affected by LDM only. This shows that lobate deposits can form in any type of crater wall and source material, either previously affected or unaffected by glacial deposits.

SU-4, SU-5, SU-7 and SU-11 contain evidence for multiple generations of gullies and all these craters host glacial deposits (Figure 10), supporting the ideas of De Haas et al. (2019b) that gullies go through phases of removal and formation as a result of glacial advance and retreat. For example, in SU-7, there appear to be five morphologically different gully types representing different generations of gully activity (Figure 10): (i) alcoves that are mantled to an extent such that its gullies and fans are completely obscured, (ii) mantled alcove but unmantled gully-fans, (iii) unmantled alcove-gully-fan, (iv) small and younger alcove-gully-fans on the crater walls that are located below the larger alcoves at the crater rim, and (v) multiple beheaded gully-fan systems. Overlapping lobes are evident on the gully types that are still connected to an alcove (ii-v), while absent on the oldest type (i) where gully deposits are largely obscured. On the gully fans of SU11, colour tones on a false colour image reveal gully fan sectors of different age. Hereon we observe that the overlapping lobate deposits are present on the two youngest sectors, which appear in tones of blue and yellow (Figure 11). This shows that only on the most recent parts of the gully fans did lobate deposits form and preserve, while on the older parts of the gully fan they did either not form or did form but were subsequently removed by post-depositional processes. 


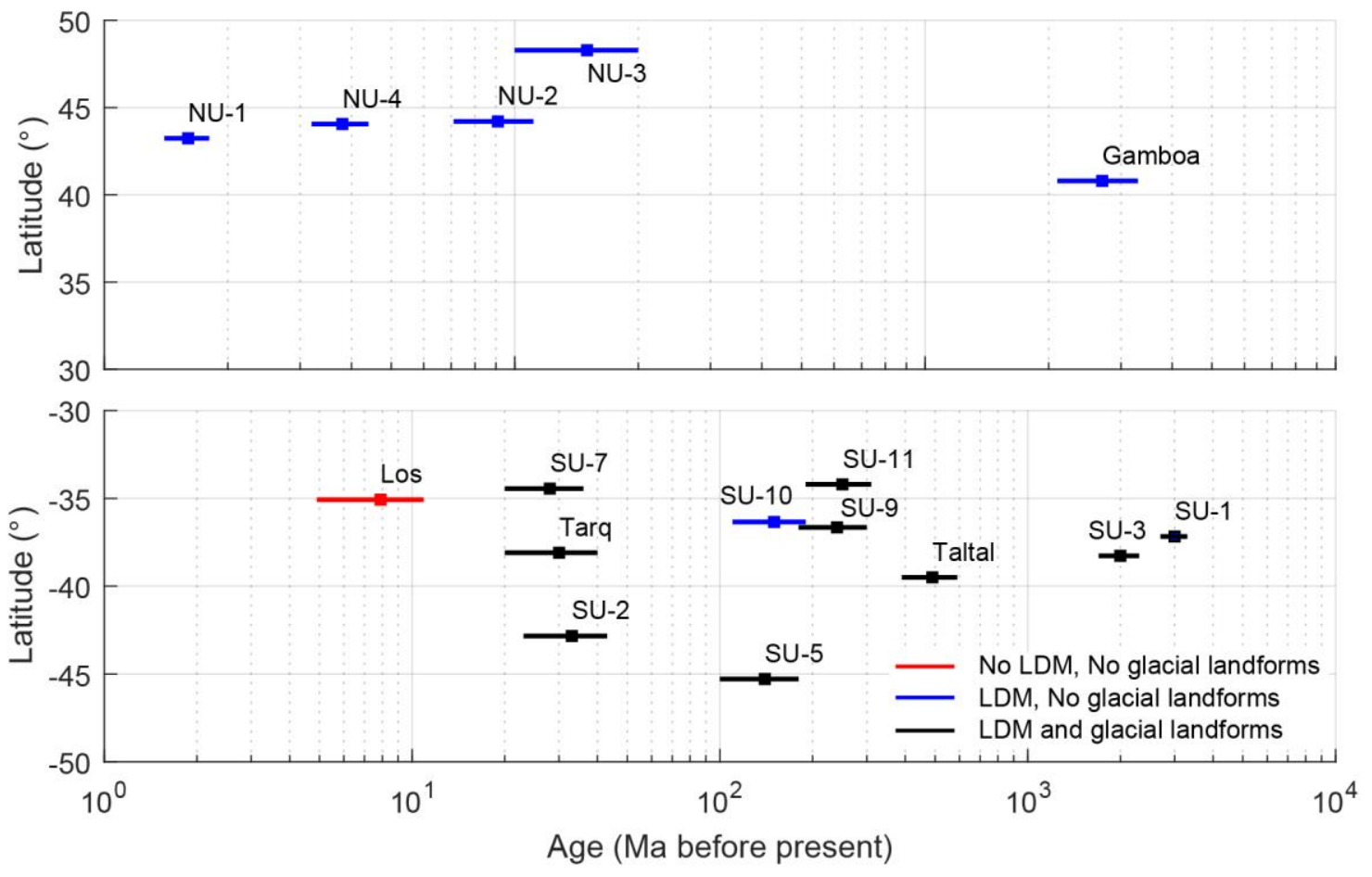

Figure 9. Maximum age of the gullies with lobate deposits, inferred from LDA (SU-2, SU-7 and Tarq) or host crater dating. 


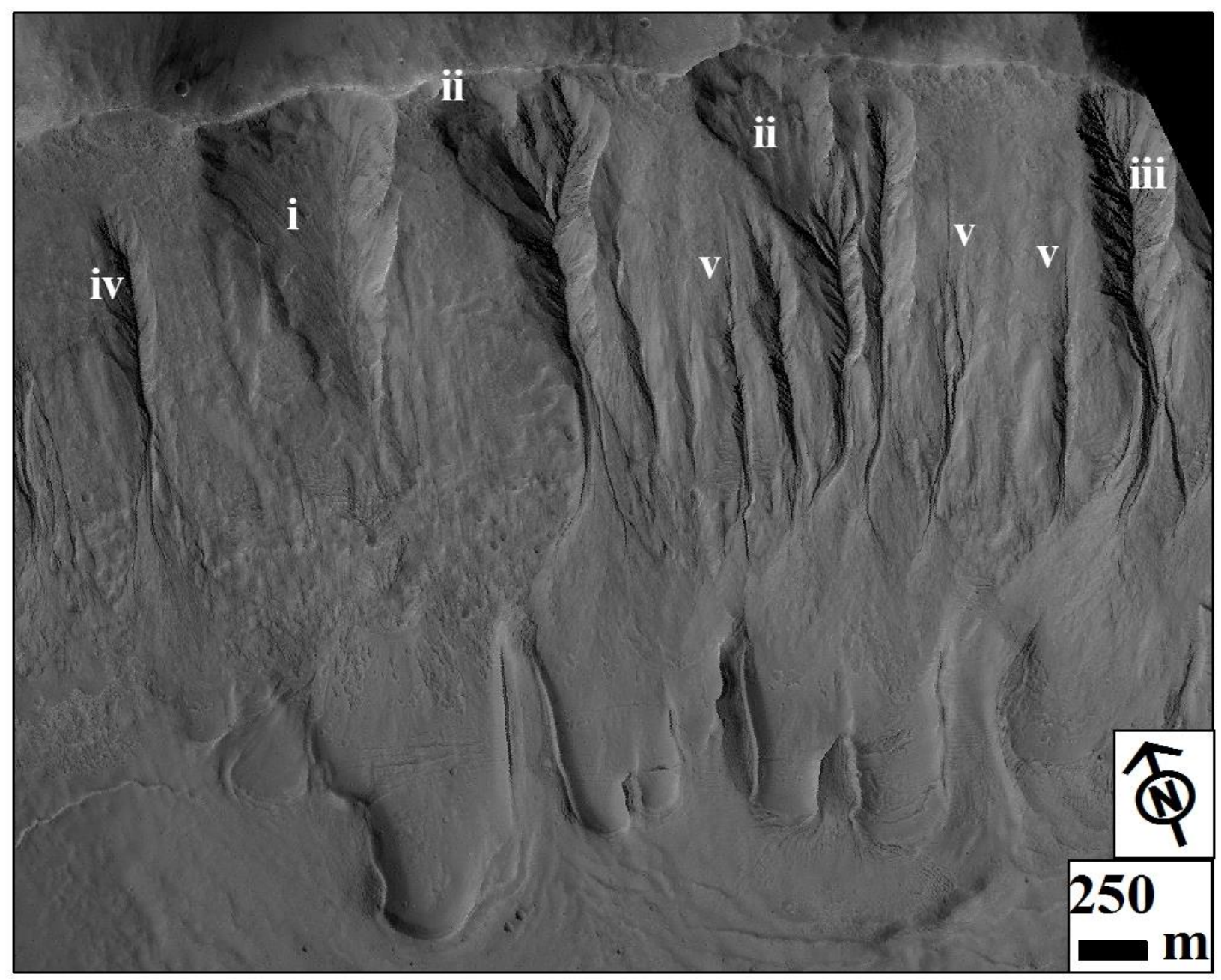

Figure 10. Different stages of gully formation and modification within SU-7 (HIRISE: ESP_013870_1450). (i) Extensively mantled alcove-gully-fan. (ii) Mantled alcove; but unmantled gully-fan. (iii) Mantled alcove-gully-fan. (iv) Possibly smaller and younger alcove-gully-fan located well below the larger gully systems over the crater wall. (v) Beheaded gully-fan systems. Image credit: NASA/JPL-Caltech/University of Arizona. 


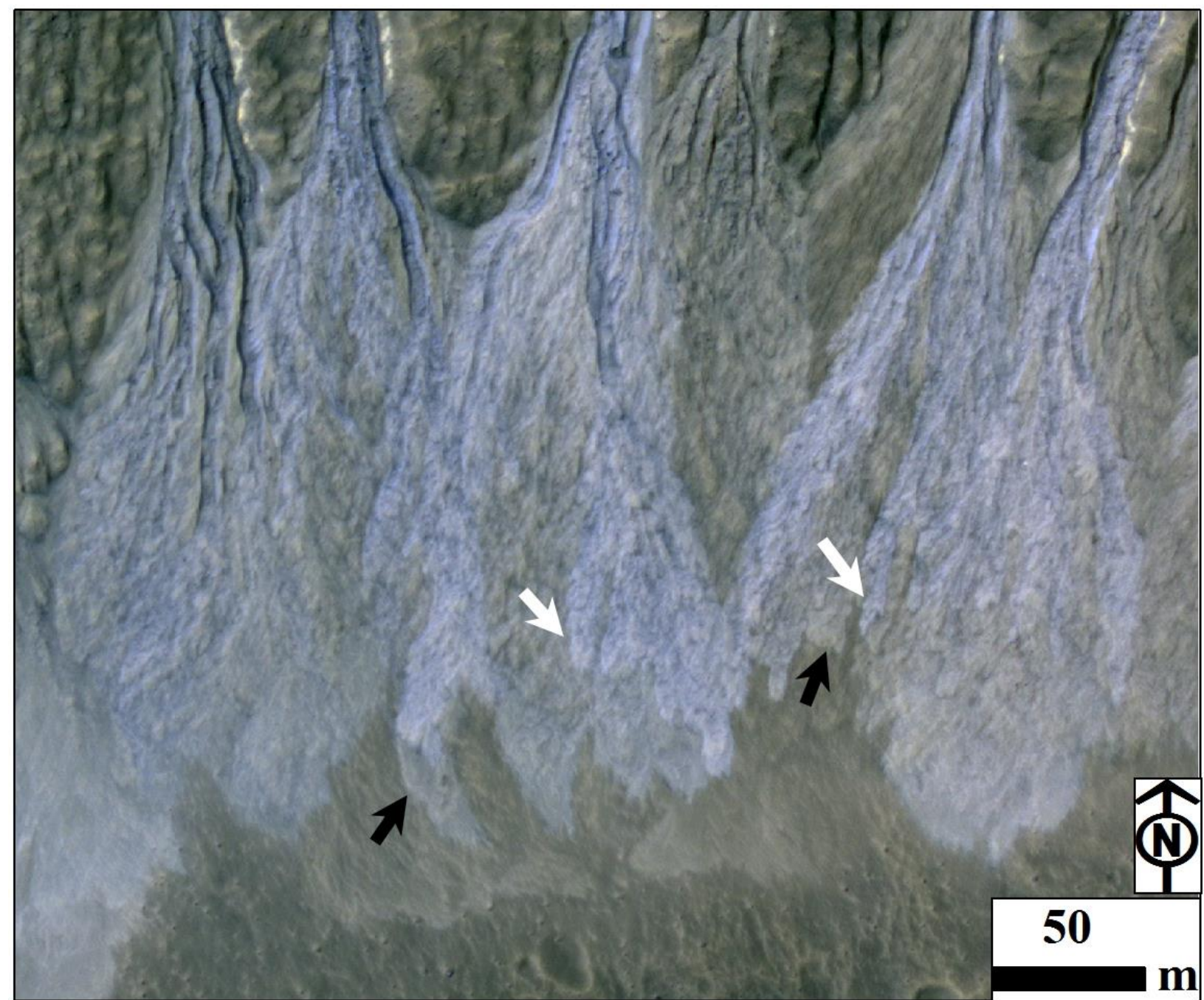

Figure 11. HiRISE false color composite image of lobate deposits within SU-11 using the IR, red and BG filters (HIRISE: ESP_047125_1455). The overlapping lobate deposits show distinct tonal appearance mainly in the shades of blue (white arrows) and yellow (black arrows), where color moves from blue to yellow with age. Image credit: NASA/JPL-Caltech/University of Arizona.

\subsection{Texture of lobate deposits}

Large numbers of clasts of varying sizes are present on the walls of craters hosting lobate deposits in the northern and southern hemispheres. In general, clasts are abundant in alcoves, along gully banks and over the fan surfaces. Embedded clasts are evident on the top, near the front and 
along the sides of individual lobes. Lobate deposits incorporating clasts are found in SU-1, SU-2, SU-3, Taltal, SU-4, SU-5, Los, SU-7, SU-9, SU-10, and SU-11 in the southern hemisphere, and NU-1, NU-3, NU-4, Gamboa and NU-5 in the northern hemisphere (Figure 12). Only in NU-2, SU-6, SU-8, and Tarq craters, the lobate deposits do not show any embedded clasts resolvable at HiRISE resolution (Figure 12q-t). 


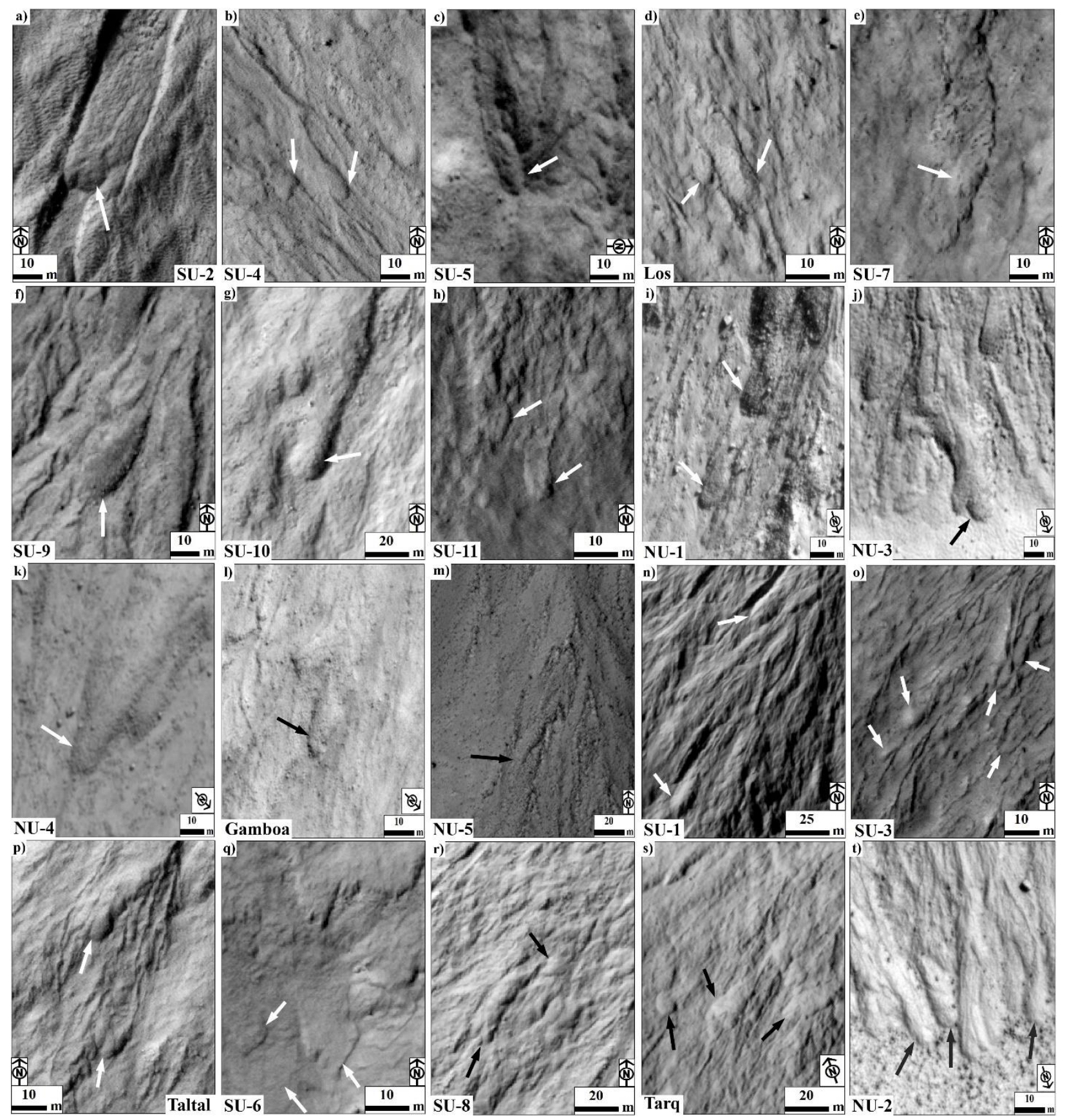

Figure 12. Zoomed-in views of lobate deposits. (a-p) Examples in which embedded clasts are evident on the top, near the front and along the sides of individual lobes. (q-t) Examples of lobes in which clasts could not be resolved. The HiRISE image Ids corresponding to the name of the craters are given in Table 1. Image credit: NASA/JPL-Caltech/University of Arizona. 


\subsection{Post-depositional modification of lobate deposits}

The older parts of the studied gully fans have a relatively smooth texture and host fewer boulders in comparison to the younger parts of the gully fans (Figure 13a-b). On the majority of the gully fans (SU-2, SU-4, SU-5, SU-6, SU-7, SU-8, SU-9, SU-10, and Tarq) (Figure 13c-d), there is a marked difference between the number of lobate deposits on the younger, upslope, parts of the fans versus the older, downslope, fan surfaces, with the younger lobes hosting more and better preserved lobate deposits. If visible on older fan surfaces, lobe margins are generally only faintly evident. The depositional lobes on the younger fan surfaces have a sharper relief and more embedded clasts than the lobes on the older fan surfaces. A few other fans have fan surfaces have been modified by aeolian activity (Taltal, SU-9, and SU-10) (Figure 13e). Some parts of the distal fan surfaces (SU-3, Los, SU-8, SU-11, and Gamboa) are obscured by dust (Figure 13f-g). In addition, some parts of the fan surfaces (SU-2, SU-6, SU-8, SU-10, Tarq, NU-1, NU-3, Gamboa, and NU-5) are covered by LDM deposits (Figure 13h-i).

The observations show that lobate deposits become progressively obscured over time, by a combination of post-depositional processes. Similar post-depositional fan surface modification has been observed on many gully-fan surfaces reported in a previous study (De Haas et al., 2015a). As lobate deposits are generally only preserved on the youngest parts of gully fans, we infer that they are deposits that formed relatively recently during the latest stages of gully activity. 

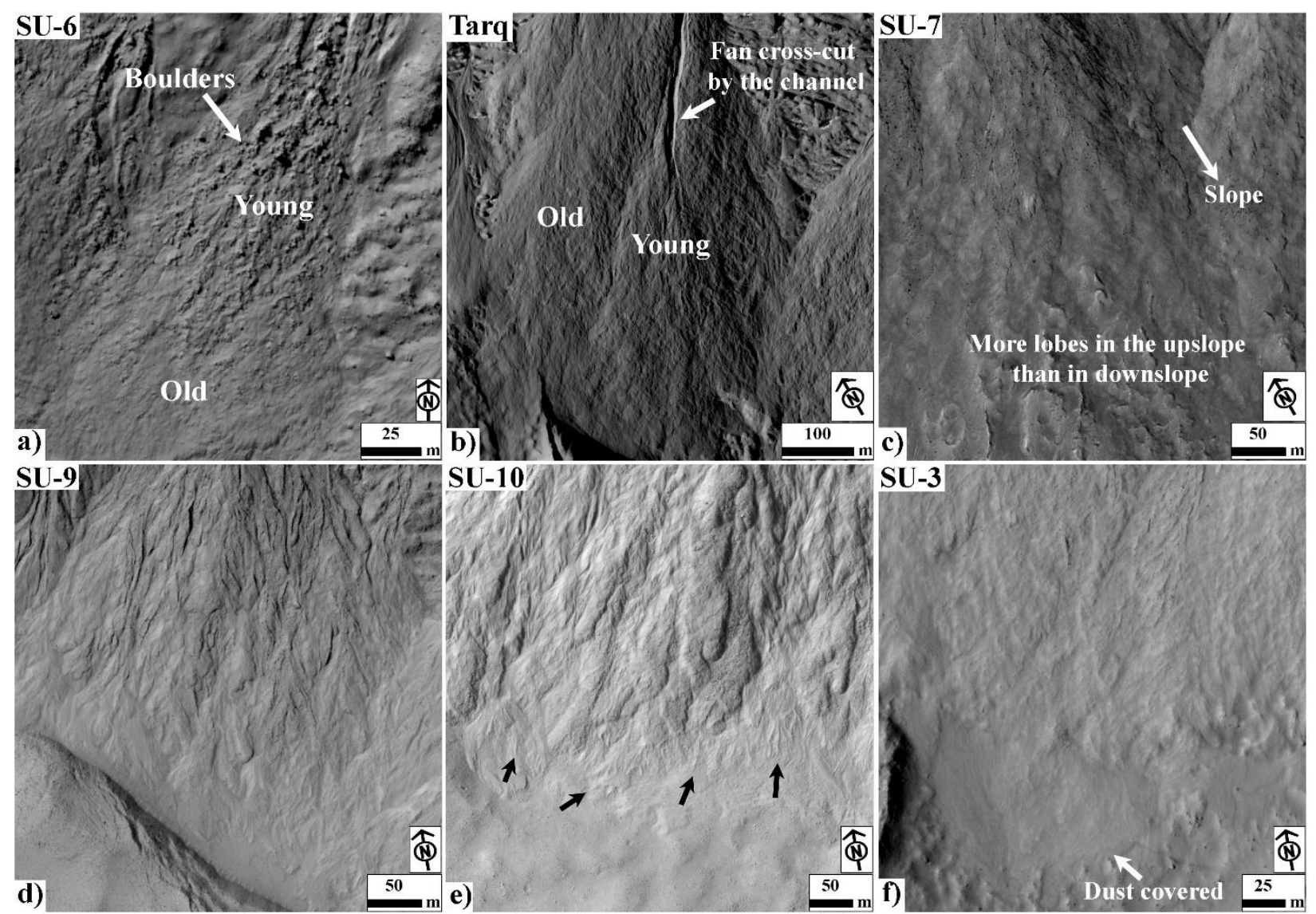

SU-3
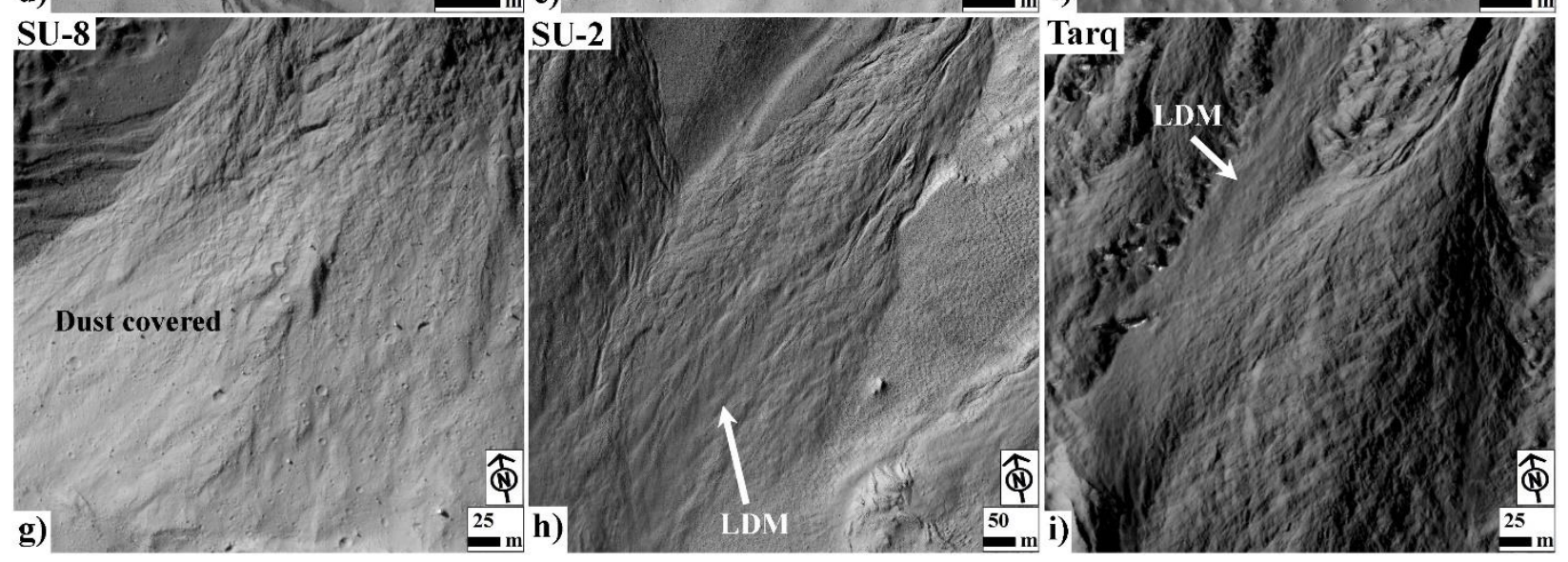

Figure 13. Examples of post-depositional modification of lobate deposits on gully-fan surfaces.

(a) Younger and older parts of the gully-fan surfaces. The younger part hosts more boulders and has more pronounced topography (HIRISE: PSP_007045_1450). (b) Olderfan surface cross-cut by a channel and superposed by a young channel-fan complex (HIRISE: ESP_036839_1420).(cd) Younger upslope fan surface hosting more lobes than an older more downslope fan surface 
(HIRISE: ESP_013870_1450, ESP_023640_1430). (e) Fan surface modification by aeolian erosion. Note that the distal part of the fan surface is reworked by aeolian erosion into ventifact or yardang-like features (HIRISE: ESP_028308_1435). (f-g) Distal fan surfaces obscured by dust (HIRISE: ESP_038473_1415, ESP_016757_1465). (h-i) Fan surfaces masked by LDM cover (HIRISE: PSP_007143_1370, ESP_036839_1420). Image credit: NASA/JPL-Caltech/University of Arizona.

\subsection{Geomorphic evidence of present-day activity}

We examine temporal HiRISE imagery for the craters where we have found lobate deposits, to determine whether the main gully systems have been active in the present-day or not. In the southern hemisphere, 8 out of the 14 craters have temporal coverage by HiRISE. For these craters, there is a HiRISE image of Martian winter, and for all these winter season images there is a corresponding HiRISE image of a different season that has a minimum temporal resolution of half a Martian year. Morphological changes only occurred within the gullies formed in SU-1 and SU-2. Here multiple dark flows have formed within the channels in the upper alcove of a main

gully system (Figure 14). These flows did not appear to have caused any change in the topography of the channels, however. In addition, recurring slope lineae (RSL) have formed nearby on the wall of SU-1 (Figure 14) (Stillman and Grimm, 2018). These appear to have originated from the rocky outcrops along the crater rim and their presence is ubiquitous at several locations where there are no gullies. It is unclear if the dark flows inside channels and RSL have a different origin mainly because morphologically they do not seem to be different. RSLs are also evident in the summer images of Taltal and Tarq (Stillman and Grimm, 2018). 
In the northern hemisphere, 4 out of the 6 craters have temporal coverage by HiRISE. HiRISE images of NU-1 and Gamboa are mainly of summer and spring seasons and despite having a temporal resolution of nearly 3 Martian years we have not observed any significant and/or minor morphological activities in these craters. None of the summer images have evidence of RSL. Nevertheless, in NU-5 we have observed evidence for defrosting in the gully in the form of dark flows (Figure 15). Nevertheless, these flows do not seem to have caused any significant change in gully topography. Apart from the aforementioned minor activity, we have not found any evidence for present-day formation of lobate deposits nor changes in which the morphology and topography of the gully is distinctly affected. 

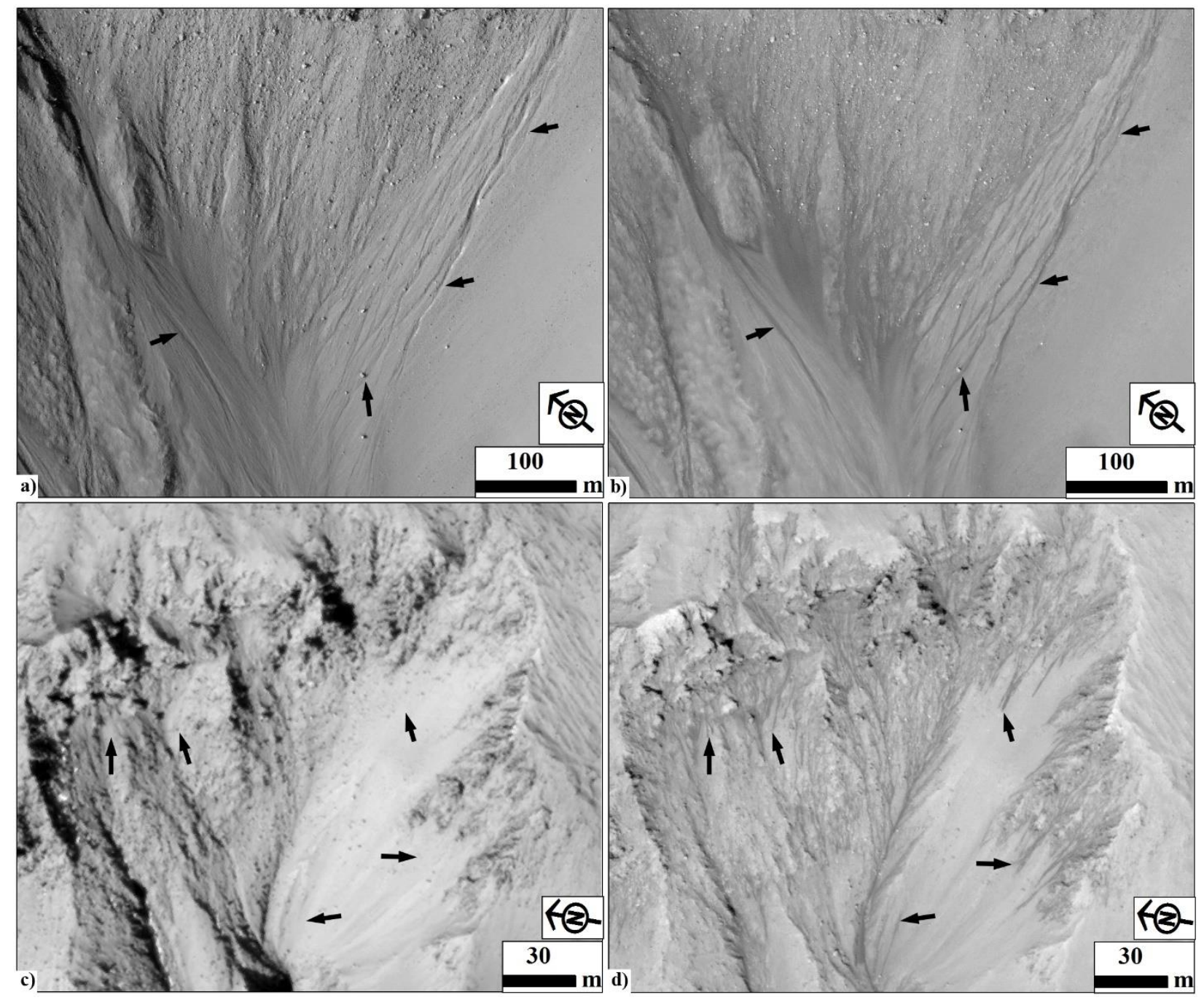

Figure 14. (a-b) Morphologic evidence of dark flows inside channels formed in SU-1 (HIRISE: ESP_036324_1425). (c-d) Multiple dark flows in the upper alcove of a gully system within SU-2 (HIRISE: PSP_007143_1370). HiRISE image acquisition details: (a) MY 29, $L_{s}: 28.9^{\circ}$, autumn season. (b) $M Y 34, L_{s}: 290.6^{\circ}$, summer season, (c) MY 32, $L_{s}: 141.5^{\circ}$, winter season. (d) $M Y 34$, $L_{s}: 288.1^{\circ}$, summer season. Image credit: NASA/JPL-Caltech/University of Arizona. 


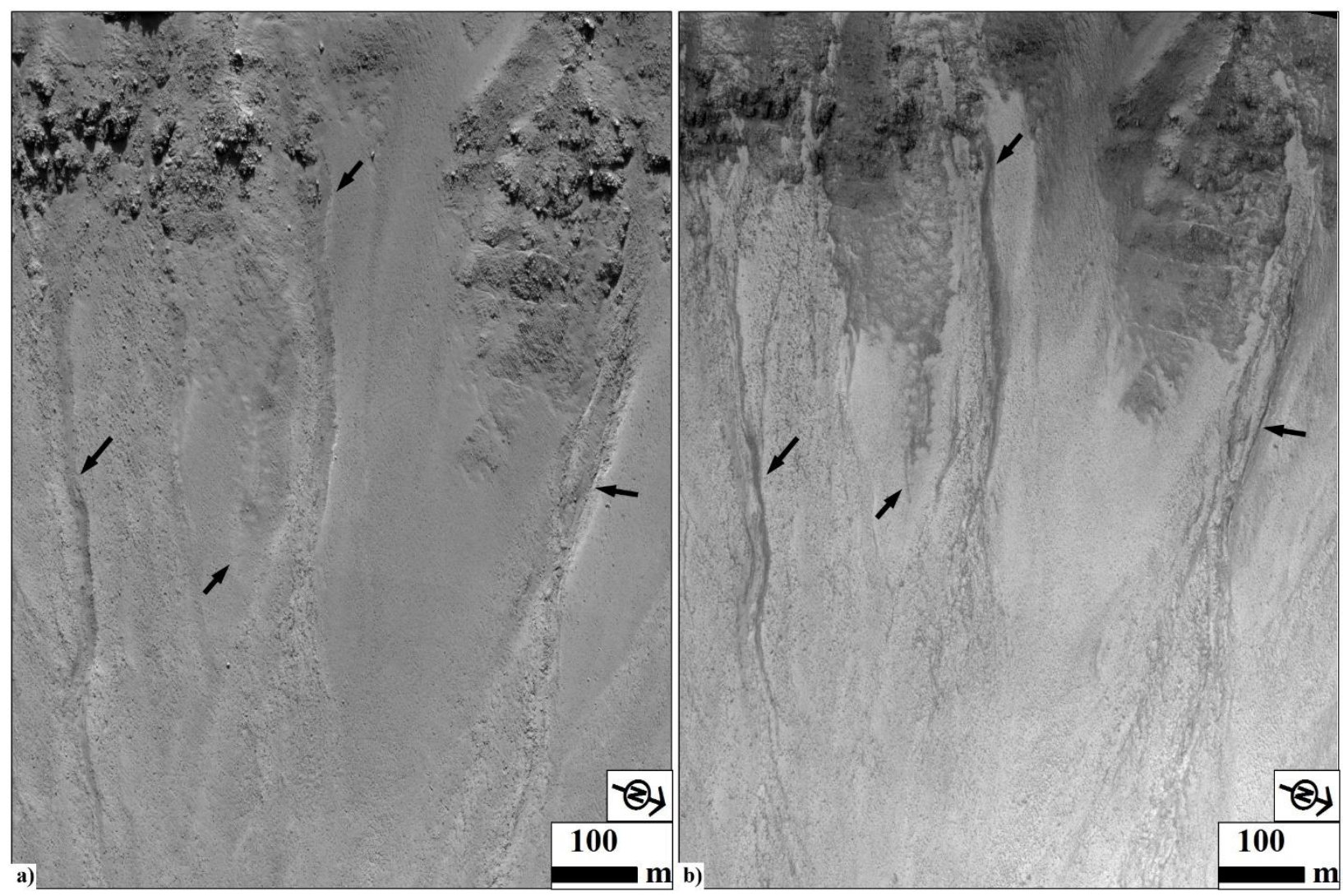

Figure 15. (a-b) Example of defrosting flows (arrows) in the gully channels formed within NU-5 (HIRISE: ESP_036501_2340). HiRISE image acquisition details: (a) MY 31, $L_{s}: 112.1^{\circ}$, summer season. (b) MY 34, Ls: 333.6 ${ }^{\circ}$ winter season. Image credit: NASA/JPL-Caltech/University of Arizona.

\section{Discussion}

Our morphological observations of overlapping lobate deposits are in agreement with previous research, which concluded that they closely resemble deposits from debris flows on Earth (Johnsson et al., 2014; De Haas et al., 2015a; Sinha et al., 2019). The key morphological attributes observed are: convex-up, tongue shaped lobes at channel termini connected to levee 
deposits along the channel margin, channel backfilling, plug formation and avulsion. Similar spatio-temporal patterns are common on debris-flow fans on Earth (De Haas et al., 2016; 2018; 2019c). The slope of lobate deposits at the foot of the martian gully-fans ranges from $18-25^{\circ}$ in the northern hemisphere and $7-19^{\circ}$ in the southern hemisphere. These slope gradients are broadly consistent with the slope values reported at the foot of the gully fans dominated by overlapping lobes in Istok, Galap, Domoni and Maricourt craters (Johnsson et al., 2014; De Haas et al., 2015a; Sinha et al., 2019). These in turn are consistent with deposition slopes of debris flow dominated alluvial fans on Earth in arid and Polar Regions (De Haas et al., 2015d) and also deposition slopes for debris flows in talus and hillslope contexts (Lee et al., 2001; Conway et al., 2011; Sinha et al., 2019).

By combining the morphological observations of gullies analysed in this study and those that are reported in literature (Lanza et al., 2010; Levy et al., 2010a; Reiss et al., 2011; Johnsson et al., 2014; De Haas et al., 2015a; Sinha et al., 2019), we have identified a total of 26 craters within $30-75^{\circ}$ latitudes on Mars in which overlapping lobate deposits are evident at the surface of gullies (Table 1). This corresponds to $3.39 \%$ in total of the 765 craters studied using HiRISE images, which implies that craters hosting lobate deposits are not common, yet they have a wide spatial distribution. We suggest that post-depositional modification of gully-fan surficial features may be crucial in hindering the identification of lobate deposits in gullies (De Haas et al., 2013). For instance, the surface of gully-fan deposits reported here and in the literature have been observed to host polygonized material, covered by LDM mantle and reworked by aeolian activity (De Haas et al., 2015a; Dickson et al., 2015). Evidence for the relative youth of these features is their location at the top of the stratigraphy of gully fans (which may or may not have evidence of underlying lobate deposits) and the presence of abundant surface clasts in the lobes in 16 craters 
in this study bearing morphological resemblance to lobes that are referred to as textured, clast-rich in Johnsson et al. (2014) and Sinha et al. (2019). For the remaining 4 craters clasts are abundant on gully banks and fan surfaces and are more similar to the lobate deposits described by Levy et al. (2010a). However, we have not observed any significant present-day changes in the morphology and topography of gullies with lobate deposits reported in this study. Only in NU-5, defrosting flows within gully channels are present in the winter HiRISE image, but no associated material transport is evident with the available data. Dundas et al. (2019) reported the formation of boulder-rich levees and a lobate deposit in Istok crater which occurred during winter coincident with $\mathrm{CO}_{2}$ frost sublimation. The relative paucity of monitoring data does not allow us to conclude whether overlapping lobate deposits are actively forming at the present-day or not, despite our morphological analysis suggesting they are relatively recent.

The gullies hosting lobate deposits reported here do not show any (1) location preference nor (2) correlation with regions reported to have high gully density (Harrison et al., 2015; Conway et al., 2019). The presence of lobate deposits inside gullied craters does not appear to be constrained by the crater's diameter. The absolute elevation of gully alcoves associated with lobate deposits shows a wide range in both the northern and southern hemispheres. We find that the dominant orientation preference for lobate deposits in the northern and southern hemispheres is poleward-facing and consistent with the previous reports for lobate deposits (Lanza et al., 2010; Reiss et al., 2011; Johnsson et al., 2014). We only find one example of equator-facing gullies with lobate deposits, which could reflect the change to equatorward-facing slopes at latitudes $>50^{\circ}$, as in Sinha et al. (2019). Our results are concordant with the orientation preference of the entire gully population (Harrison et al., 2015; Conway et al., 2019), which shows a transition from poleward-facing to mixed preference around $40^{\circ}$ latitude. 
Despite the presence of LDM deposits in all the craters containing lobate deposits in the northern hemisphere, there is no evidence for the presence of glacial landforms. In the southern hemisphere, all but 4 out of 14 craters contain morphological evidence for glaciation and all but one crater (Los crater) contain LDM deposits, as shown by the softened appearance of the crater wall and infilled alcoves. Among the previously reported craters hosting lobate deposits, Istok, Galap and Maricourt are the craters in which there is no evidence of glacial landforms and LDM deposits (Johnsson et al., 2014; De Haas et al., 2015a; Sinha et al., 2019). Therefore, lobate deposits are not associated with any particular landscape feature, being found in craters without LDM, with LDM and with both LDM and signs of glaciation, similarly with the gully population as a whole (e.g., De Haas et al., 2019b).

The craters containing lobate deposits studied here show a maximum and minimum age of $\sim 3.0 \mathrm{Ga}$ and $\sim 1.6 \mathrm{Ma}$, respectively. This implies that lobate deposits thus form on gullies in craters of all ages. Notably, the number of young craters $(<10 \mathrm{Ma})$ is larger in the northern hemisphere (4 craters) in comparison to only 1 crater (Los) in the southern hemisphere. Los is the only young crater that lacks both glacial and LDM deposits. For all other craters, morphological evidence for LDM is present regardless of host crater age. Craters that are unaffected by glaciation do not show a relationship with their age, i.e. craters with age $<10 \mathrm{Ma}$ and $>10 \mathrm{Ma}$ both lack evidence of glaciation. There are 4 craters that have preserved evidence for episodic gully formation, regardless of their age. Again, these findings are consistent with the gully population as a whole, where gullies are found on steep slopes regardless of their age of formation.

In summary, the lack of particular spatial, orientation or landscape context for the lobate deposits within the general martian gully population argues that the presence of lobate deposits is not due to a specific process occurring in any given context, but rather a result of preservation of 
the deposits. We argue that the process forming lobate deposits has been active more widely, but that its morphological expression has been hidden by post-depositional processes (De Haas et al., 2013, 2015a; Dickson et al., 2015). Further, our results suggest that debris-flow-like processes are important for the formation of the lobate deposits and by extension gully-fans on Mars and therefore the transport of sediment through gullies. To produce deposits that resemble those produced by debris flows on Earth, implies the involvement of a fluidizing agent, which is most likely to be $\mathrm{CO}_{2}$ (De Haas et al., 2019a) and/or liquid water (Johnsson et al., 2014). The surface environment of Mars under present climate conditions does not allow for sufficient accumulation of liquid water necessary to mobilise a debris flow, but these conditions could have occurred in the last few million years (e.g., De Haas et al. 2015b). Our data do not allow us to determine if these processes are continuing at the present day, but the observation of new lobate deposits in Istok crater in winter by Dundas et al. (2019) suggests these processes could be ongoing. If substantiated by future observations, this would imply that sublimating $\mathrm{CO}_{2}$ is capable of producing debris-flow like deposits. Dundas et al. (2019) outline the mechanism by which sublimating $\mathrm{CO}_{2}$ mobilises sediment, as follows: a mix of sediment and $\mathrm{CO}_{2}$ ice fails and its potential energy is converted into kinetic energy and consumed in the phase change of $\mathrm{CO}_{2}$ ice to gas while falling downslope within a gully channel, and input of additional heat from eroded sediment should maintain the gas generation (Dundas et al., 2019; De Haas et al., 2019a). A recent modelling study has revealed that even small volumetric fractions of $\mathrm{CO}_{2}$ frost $(<1 \%)$ within mass flows can generate gas fluxes adequate to fluidize present-day flows in gullies (De Haas et al., 2019a). There are important physical differences between gas-supported granular flows and liquid supported ones, which should result in morphological differences, but detailed numerical or laboratory investigations would be needed to infer these. Hence, we leave open the possibility that 
such deposits could be created via water-saturated debris flows under different, yet recent climate conditions.

\section{Conclusions}

We have analysed the geographical distribution of overlapping lobate deposits, their morphological characteristics, slope relationships, orientation preferences, surface texture, characteristics of their host craters, evidence of LDM and former ice-related landforms, and age relationships to ultimately speculate on their formation mechanisms.

We have identified 26 craters in which lobate deposits occur in gullies, of which 6 were previously reported. Of these sites 8 are in the northern hemisphere and 18 are in the southern hemisphere. We find that gullies with overlapping lobate deposits are not differentiable from the general population, they have similar spatial distribution, orientation, host-crater age range and landscape settings. We infer that the expression of lobate deposits within gullies is based on the preservation of these deposits, wherein, in the older gully fans, the morphological signature of the lobate deposits has been erased by secondary processes, as suggested by De Haas et al. (2015a). This inference is supported by evidence for the relatively young age of these deposits compared to other gully-fans, based on our observations of superposition relationships and their association with abundant clasts.

Our observations of overlapping convex-up, tongue shaped terminal lobes, lateral deposits (levees), channel backfilling, plug formation and avulsion and steep deposition slopes (18-25 in the northern and $7-19^{\circ}$ in the southern hemisphere), also typical in terrestrial debris flows, reinforce the previous interpretation that these deposits are a result of a debris flow-like process. 
Our data do not allow us to distinguish whether the fluidising agent for this process is sublimating $\mathrm{CO}_{2}$ ice or liquid water under past climate conditions.

\section{Acknowledgements}

RKS and DR acknowledges the financial support by the Indian Space Research Organisation, Department of Space, Government of India. TdH was funded by the Dutch Science Foundation, grant 016.Veni.192.001. We gratefully acknowledge the engineering and science teams of MRO for acquisition of the datasets used in this study. We acknowledge the efforts of team MUTED to develop an online tool for quick identification of the spatial and multi-temporal coverage of planetary image data from Mars. Some of the datasets used in this work have been processed with the MarsSI (emars.univ-lyon1.fr) application founded by the European Union's Seventh Framework Program (FP7/2007-2013) (ERC Grant Agreement No. 280168). This work is a part of the PhD work of RKS. Director PRL, Head of Planetary Science Division, PRL, and Director IIT Gandhinagar are gratefully acknowledged for constant encouragement during the work.

\section{References}

Arfstrom, J. and Hartmann, W.K., 2005. Martian flow features, moraine-like ridges, and gullies: Terrestrial analogs and interrelationships. Icarus, 174(2), pp.321-335.

Baker, D.M., Head, J.W. and Marchant, D.R., 2010. Flow patterns of lobate debris aprons and lineated valley fill north of Ismeniae Fossae, Mars: Evidence for extensive mid-latitude glaciation in the Late Amazonian. Icarus, 207(1), pp.186-209.

Balme, M., Mangold, N., Baratoux, D., Costard, F., Gosselin, M., Masson, P., Pinet, P. and Neukum, G., 2006. Orientation and distribution of recent gullies in the southern hemisphere of Mars: observations from High Resolution Stereo Camera/Mars Express (HRSC/MEX) and Mars 
Orbiter Camera/Mars Global Surveyor (MOC/MGS) data. Journal of Geophysical Research: Planets, 111(E5).

Bart, G.D., 2007. Comparison of small lunar landslides and Martian gullies. Icarus, 187(2), pp.417-421.

Cedillo-Flores, Y., Treiman, A.H., Lasue, J. and Clifford, S.M., 2011. CO2 gas fluidization in the initiation and formation of Martian polar gullies. Geophysical Research Letters, 38(21).

Christensen, P.R., 2003. Formation of recent Martian gullies through melting of extensive waterrich snow deposits. Nature, 422(6927), p.45.

Conway, S.J., Balme, M.R., Kreslavsky, M.A., Murray, J.B. and Towner, M.C., 2015. The comparison of topographic long profiles of gullies on Earth to gullies on Mars: a signal of water on Mars. Icarus, 253, pp.189-204.

Conway, S.J., Balme, M.R., Murray, J.B., Towner, M.C. and Kim, J.R., 2008. Icelandic debris flows and their relationship to martian gullies. LPI Contributions, 1303, pp.25-26.

Conway, S.J., Balme, M.R., Murray, J.B., Towner, M.C., Okubo, C.H. and Grindrod, P.M., 2011. The indication of Martian gully formation processes by slope-area analysis. Geological Society, London, Special publications, 356(1), pp.171-201.

Conway, S.J., Butcher, F.E., De Haas, T., Deijns, A.A., Grindrod, P.M. and Davis, J.M., 2018. Glacial and gully erosion on Mars: A terrestrial perspective. Geomorphology, 318, pp.26-57.

Conway, S.J., Harrison, T.N., Soare, R.J., Britton, A.W. and Steele, L.J., 2019. New slopenormalized global gully density and orientation maps for Mars. Geological Society, London, Special Publications, 467(1), pp.187-197.

Costard, F., Forget, F., Mangold, N. and Peulvast, J.P., 2002. Formation of recent Martian debris flows by melting of near-surface ground ice at high obliquity. Science, 295(5552), pp.110-113.

De Haas, T., Hauber, E. and Kleinhans, M.G., 2013. Local late Amazonian boulder breakdown and denudation rate on Mars. Geophysical Research Letters, 40(14), pp.3527-3531. 
De Haas, T., Ventra, D., Hauber, E., Conway, S.J. and Kleinhans, M.G., 2015a. Sedimentological analyses of Martian gullies: the subsurface as the key to the surface. Icarus, 258, pp.92-108.

De Haas, T., Hauber, E., Conway, S.J., Van Steijn, H., Johnsson, A. and Kleinhans, M.G., $2015 b$. Earth-like aqueous debris-flow activity on Mars at high orbital obliquity in the last million years. Nature communications, 6, p.7543.

De Haas, T., Braat, L., Leuven, J.R., Lokhorst, I.R. and Kleinhans, M.G., 2015c. Effects of debris flow composition on runout, depositional mechanisms, and deposit morphology in laboratory experiments. Journal of Geophysical Research: Earth Surface, 120(9), pp.1949-1972.

De Haas, T., Kleinhans, M.G., Carbonneau, P.E., Rubensdotter, L. and Hauber, E., 2015d. Surface morphology of fans in the high-Arctic periglacial environment of Svalbard: Controls and processes. Earth-Science Reviews, 146, pp.163-182.

De Haas, T., van den Berg, W., Braat, L. and Kleinhans, M.G., 2016. Autogenic avulsion, channelization and backfilling dynamics of debris-flow fans. Sedimentology, 63(6), pp.15961619.

De Haas, T., Densmore, A.L., Stoffel, M., Suwa, H., Imaizumi, F., Ballesteros-Cánovas, J.A. and Wasklewicz, T., 2018. Avulsions and the spatio-temporal evolution of debris-flow fans. EarthScience Reviews, 177, pp.53-75.

De Haas, T., McArdell, B.W., Conway, S.J., McElwaine, J.N., Kleinhans, M.G., Salese, F. and Grindrod, P.M., 2019a. Initiation and flow conditions of contemporary flows in Martian gullies. Journal of Geophysical Research: Planets.

De Haas, T., Conway, S.J., Butcher, F.E.G., Levy, J., Grindrod, P.M., Goudge, T.A. and Balme, M.R., 2019b. Time will tell: temporal evolution of Martian gullies and palaeoclimatic implications. Geological Society, London, Special Publications, 467(1), pp.165-186.

De Haas, T., Densmore, A.L., Hond, T. and Cox, N.J., 2019c. Fan-surface evidence for debrisflow avulsion controls and probabilities, Saline Valley, California. Journal of geophysical research: earth surface,124(5), pp.1118-1138. 
Dickson, J.L. and Head, J.W., 2009. The formation and evolution of youthful gullies on Mars: Gullies as the late-stage phase of Mars' most recent ice age. Icarus, 204(1), pp.63-86.

Dickson, J.L., Head, J.W., Goudge, T.A. and Barbieri, L., 2015. Recent climate cycles on Mars: Stratigraphic relationships between multiple generations of gullies and the latitude dependent mantle. Icarus, 252, pp.83-94.

Diniega, S., Byrne, S., Bridges, N.T., Dundas, C.M. and McEwen, A.S., 2010. Seasonality of present-day Martian dune-gully activity. Geology, 38(11), pp.1047-1050.

Dundas, C.M., Diniega, S. and McEwen, A.S., 2015. Long-term monitoring of martian gully formation and evolution with MRO/HiRISE. Icarus, 251, pp.244-263.

Dundas, C.M., Diniega, S., Hansen, C.J., Byrne, S. and McEwen, A.S., 2012. Seasonal activity and morphological changes in Martian gullies. Icarus, 220(1), pp.124-143.

Dundas, C.M., McEwen, A.S., Diniega, S., Byrne, S. and Martinez-Alonso, S., 2010. New and recent gully activity on Mars as seen by HiRISE. Geophysical Research Letters, 37(7).

Dundas, C.M., McEwen, A.S., Diniega, S., Hansen, C.J., Byrne, S. and McElwaine, J.N., 2019. The formation of gullies on Mars today. Geological Society, London, Special Publications, 467(1), pp.67-94.

Erkeling, G., Luesebrink, D., Hiesinger, H., Reiss, D., Heyer, T. and Jaumann, R., 2016. The Multi-Temporal Database of Planetary Image Data (MUTED): A database to support the identification of surface changes and short-lived surface processes. Planetary and Space Science, 125 , pp.43-61.

Haberle, R.M., McKay, C.P., Schaeffer, J., Cabrol, N.A., Grin, E.A., Zent, A.P. and Quinn, R., 2001. On the possibility of liquid water on present-day Mars. Journal of Geophysical Research: Planets, 106(E10), pp.23317-23326.

Hansen, C.J., Bourke, M., Bridges, N.T., Byrne, S., Colon, C., Diniega, S., Dundas, C., Herkenhoff, K., McEwen, A., Mellon, M. and Portyankina, G., 2011. Seasonal erosion and restoration of Mars' northern polar dunes. Science, 331(6017), pp.575-578. 
Harrison, T.N., Osinski, G.R., Tornabene, L.L. and Jones, E., 2015. Global documentation of gullies with the Mars Reconnaissance Orbiter Context Camera and implications for their formation. Icarus, 252, pp.236-254.

Hartmann, W.K., Thorsteinsson, T. and Sigurdsson, F., 2003. Martian hillside gullies and Icelandic analogs. Icarus, 162(2), pp.259-277.

Head, J.W., Marchant, D.R. and Kreslavsky, M.A., 2008. Formation of gullies on Mars: Link to recent climate history and insolation microenvironments implicate surface water flow origin. Proceedings of the National academy of Sciences, 105(36), pp.13258-13263.

Head, J.W., Marchant, D.R., Dickson, J.L., Kress, A.M. and Baker, D.M., 2010. Northern midlatitude glaciation in the Late Amazonian period of Mars: Criteria for the recognition of debriscovered glacier and valley glacier landsystem deposits. Earth and Planetary Science Letters, 294(34), pp.306-320.

Head, J.W., Mustard, J.F., Kreslavsky, M.A., Milliken, R.E. and Marchant, D.R., 2003. Recent ice ages on Mars. Nature, 426(6968), p.797.

Hecht, M.H., 2002. Metastability of liquid water on Mars. Icarus, 156(2), pp.373-386.

Heldmann, J.L. and Mellon, M.T., 2004. Observations of Martian gullies and constraints on potential formation mechanisms. Icarus, 168(2), pp.285-304.

Heldmann, J.L., Carlsson, E., Johansson, H., Mellon, M.T. and Toon, O.B., 2007. Observations of Martian gullies and constraints on potential formation mechanisms: II. The northern hemisphere. Icarus, 188(2), pp.324-344.

Heyer, T., Hiesinger, H., Reiss, D., Erkeling, G., Bernhardt, H., Luesebrink, D. and Jaumann, R., 2018. The Multi-Temporal Database of Planetary Image Data (MUTED): A web-based tool for studying dynamic Mars. Planetary and Space Science, 159, pp.56-65.

Hoffman, N., 2002. Active polar gullies on Mars and the role of carbon dioxide. Astrobiology, 2(3), pp.313-323. 
Hubbard, B., Milliken, R.E., Kargel, J.S., Limaye, A. and Souness, C., 2011. Geomorphological characterisation and interpretation of a mid-latitude glacier-like form: Hellas Planitia, Mars. Icarus, 211(1), pp.330-346.

Ingersoll, A.P., 1970. Mars: Occurrence of liquid water. Science, 168(3934), pp.972-973.

Ishii, T. and Sasaki, S., 2004, March. Formation of recent Martian gullies by avalanches of CO2 frost. In Lunar and Planetary Science Conference (Vol. 35).

Ivanov, B.A., 2001. Mars/Moon cratering rate ratio estimates. Space Science Reviews, 96(1-4), pp.87-104.

Johnsson, A., Reiss, D., Hauber, E., Hiesinger, H. and Zanetti, M., 2014. Evidence for very recent melt-water and debris flow activity in gullies in a young mid-latitude crater on Mars. Icarus, 235, pp.37-54.

Kneissl, T., van Gasselt, S. and Neukum, G., 2011. Map-projection-independent crater sizefrequency determination in GIS environments-New software tool for ArcGIS. Planetary and Space Science, 59(11-12), pp.1243-1254.

Kreslavsky, M.A. and Head III, J.W., 2002. Mars: Nature and evolution of young latitudedependent water-ice-rich mantle. Geophysical Research Letters, 29(15), pp.14-1.

Kress, A.M. and Head, J.W., 2008. Ring-mold craters in lineated valley fill and lobate debris aprons on Mars: Evidence for subsurface glacial ice. Geophysical Research Letters, 35(23).

Lanza, N.L., Meyer, G.A., Okubo, C.H., Newsom, H.E. and Wiens, R.C., 2010. Evidence for debris flow gully formation initiated by shallow subsurface water on Mars. Icarus, 205(1), pp.103112.

Lee, P., Cockell, C.S., Marinova, M.M., McKay, C.P. and Rice Jr, J.W., 2001. Snow and ice melt flow features on Devon Island, Nunavut, Arctic Canada as possible analogs for recent slope flow features on Mars. 
Levy, J., Head, J.W. and Marchant, D.R., 2010b. Concentric crater fill in the northern mid-latitudes of Mars: Formation processes and relationships to similar landforms of glacial origin. Icarus, 209(2), pp.390-404.

Levy, J.S., Head, J.W. and Marchant, D.R., 2009. Concentric crater fill in Utopia Planitia: History and interaction between glacial "brain terrain" and periglacial mantle processes. Icarus, 202(2), pp.462-476.

Levy, J.S., Head, J.W., Dickson, J.L., Fassett, C.I., Morgan, G.A. and Schon, S.C., 2010a. Identification of gully debris flow deposits in Protonilus Mensae, Mars: Characterization of a water-bearing, energetic gully-forming process. Earth and Planetary Science Letters, 294(3-4), pp.368-377.

Lozac'h, L., Quantin-Nataf, C., Loizeau, D., Clenet, H., Bultel, B., Allemand, P., Thollot, P., Fernando, J., Ody, A. and Harrison, S., 2015, October. MarsSI: Martian surface Data processing Application. In European Planetary Science Congress (Vol. 10).

Malin, M.C. and Edgett, K.S., 2000. Evidence for recent groundwater seepage and surface runoff on Mars. Science, 288(5475), pp.2330-2335.

Mangold, N., Costard, F. and Forget, F., 2003. Debris flows over sand dunes on Mars: Evidence for liquid water. Journal of Geophysical Research: Planets, 108(E4).

Mangold, N., Mangeney, A., Migeon, V., Ansan, V., Lucas, A., Baratoux, D. and Bouchut, F., 2010. Sinuous gullies on Mars: Frequency, distribution, and implications for flow properties. Journal of Geophysical Research: Planets, 115(E11).

McEwen, A.S., 2018, March. The Future of MRO/HiRISE. In Lunar and Planetary Science Conference (Vol. 49).

McEwen, A.S., Eliason, E.M., Bergstrom, J.W., Bridges, N.T., Hansen, C.J., Delamere, W.A., Grant, J.A., Gulick, V.C., Herkenhoff, K.E., Keszthelyi, L. and Kirk, R.L., 2007b. Mars reconnaissance orbiter's high resolution imaging science experiment (HiRISE). Journal of Geophysical Research: Planets, 112(E5). 
McEwen, A.S., Hansen, C.J., Delamere, W.A., Eliason, E.M., Herkenhoff, K.E., Keszthelyi, L., Gulick, V.C., Kirk, R.L., Mellon, M.T., Grant, J.A. and Thomas, N., 2007a. A closer look at waterrelated geologic activity on Mars. Science, 317(5845), pp.1706-1709.

Michael, G.G., Platz, T., Kneissl, T. and Schmedemann, N., 2012. Planetary surface dating from crater size-frequency distribution measurements: Spatial randomness and clustering. Icarus, 218(1), pp.169-177.

Morgan, G.A., Head, J.W., Forget, F., Madeleine, J.B. and Spiga, A., 2010. Gully formation on Mars: Two recent phases of formation suggested by links between morphology, slope orientation and insolation history. Icarus, 208(2), pp.658-666.

Mustard, J.F., Cooper, C.D. and Rifkin, M.K., 2001. Evidence for recent climate change on Mars from the identification of youthful near-surface ground ice. Nature, 412(6845), p.411.

Noe Dobrea, E.Z., Asphaug, E., Grant, J.A., Kessler, M.A. and Mellon, M.T., 2007, July. Patterned ground as an alternative explanation for the formation of brain coral textures in the mid latitudes of Mars: HiRISE observations of lineated valley fill textures. In Seventh International Conference on Mars (Vol. 1353, p. 3358).

Pasquon, K., Gargani, J., Massé, M., Vincendon, M., Conway, S.J., Séjourné, A., Jomelli, V., Balme, M.R., Lopez, S. and Guimpier, A., 2019a. Present-day development of gully-channel sinuosity by carbon dioxide gas supported flows on Mars. Icarus, 329, pp.296-313.

Pasquon, K., Gargani, J., Nachon, M., Conway, S.J., Massé, M., Jouannic, G., Balme, M.R., Costard, F. and Vincendon, M., 2019b. Are different Martian gully morphologies due to different processes on the Kaiser dune field?. Geological Society, London, Special Publications, 467(1), pp.145-164.

Pelletier, J.D., Kolb, K.J., McEwen, A.S. and Kirk, R.L., 2008. Recent bright gully deposits on Mars: Wet or dry flow?. Geology, 36(3), pp.211-214.

Pilorget, C. and Forget, F., 2016. Formation of gullies on Mars by debris flows triggered by CO 2 sublimation. Nature Geoscience, 9(1), p.65. 
Quantin-Nataf, C., Lozac'h, L., Thollot, P., Loizeau, D., Bultel, B., Fernando, J., Allemand, P., Dubuffet, F., Poulet, F., Ody, A. and Clenet, H., 2018. MarsSI: Martian surface data processing information system. Planetary and Space Science, 150, pp.157-170.

Reiss, D. and Jaumann, R., 2003. Recent debris flows on Mars: Seasonal observations of the Russell Crater dune field. Geophysical Research Letters, 30(6).

Reiss, D., Hauber, E., Hiesinger, H., Jaumann, R., Trauthan, F., Preusker, F., Zanetti, M., Ulrich, M., Johnsson, A., Johansson, L. and Olvmo, M., 2011. Terrestrial gullies and debris-flow tracks on Svalbard as planetary analogs for Mars. Geological Society of America Special Papers, 483, pp.165-175.

Reiss, D., Hiesinger, H., Hauber, E. and Gwinner, K., 2009. Regional differences in gully occurrence on Mars: A comparison between the Hale and Bond craters. Planetary and Space Science, 57(8-9), pp.958-974.

Richardson, M.I. and Mischna, M.A., 2005. Long-term evolution of transient liquid water on Mars. Journal of Geophysical Research: Planets, 110(E3).

Sears, D.W. and Moore, S.R., 2005. On laboratory simulation and the evaporation rate of water on Mars. Geophysical research letters, 32(16).

Sinha, R.K. and Vijayan, S., 2017. Geomorphic investigation of craters in Alba Mons, Mars: Implications for Late Amazonian glacial activity in the region. Planetary and Space Science, 144, pp.32-48.

Sinha, R.K., Vijayan, S., Shukla, A.D., Das, P. and Bhattacharya, F., 2019. Gullies and debrisflows in Ladakh Himalaya, India: a potential Martian analogue. Geological Society, London, Special Publications, 467(1), pp.315-342.

Smith, D.E., Zuber, M.T., Frey, H.V., Garvin, J.B., Head, J.W., Muhleman, D.O., Pettengill, G.H., Phillips, R.J., Solomon, S.C., Zwally, H.J. and Banerdt, W.B., 2001. Mars Orbiter Laser Altimeter: Experiment summary after the first year of global mapping of Mars. Journal of Geophysical Research: Planets, 106(E10), pp.23689-23722. 
Stillman, D.E. and Grimm, R.E., 2018. Two pulses of seasonal activity in martian southern midlatitude recurring slope lineae (RSL). Icarus, 302, pp.126-133.

Tao, Y., Muller, J.P., Sidiropoulos, P., Xiong, S.T., Putri, A.R.D., Walter, S.H.G., VeitchMichaelis, J. and Yershov, V., 2018. Massive stereo-based DTM production for Mars on cloud computers. Planetary and Space Science, 154, pp.30-58.

Tesson, P.A., Conway, S.J., Mangold, N., Ciazela, J., Lewis, S.R. and Mège, D., 2019. Evidence for thermal-stress-induced rockfalls on Mars impact crater slopes. Icarus, p.113503.

Treiman, A.H., 2003. Geologic settings of Martian gullies: Implications for their origins. Journal of Geophysical Research: Planets, 108(E4). 


\begin{tabular}{|c|c|c|c|c|c|c|c|c|c|c|}
\hline $\begin{array}{l}\text { Crater } \\
\text { name }\end{array}$ & Lat./Long. & $\begin{array}{c}\text { Diam } \\
\text { eter }\end{array}$ & $\begin{array}{l}\text { Alcove } \\
\text { elevation }\end{array}$ & $\begin{array}{c}\text { Slope (at } \\
\text { lobate } \\
\text { deposits/mi } \\
\text { ddle/top) }\end{array}$ & $\begin{array}{c}\text { Gully/lobate } \\
\text { deposit } \\
\text { orientation }\end{array}$ & $\begin{array}{c}\begin{array}{c}\text { Evidence } \\
\text { of } \\
\text { LDM/Glac } \\
\text { iation }\end{array} \\
\end{array}$ & $\begin{array}{c}\text { Best-fit age, } \\
\text { crater } \\
\text { diameter, } \\
\text { count area }\end{array}$ & HiRISE Id & CTX Id & Reference \\
\hline \multicolumn{11}{|c|}{ Craters hosting lobate deposits in the northern hemisphere } \\
\hline $\begin{array}{l}\text { Unnamed } \\
(\mathrm{NU}-1)\end{array}$ & $\begin{array}{l}43.24^{\circ} \mathrm{N} \\
134.20^{\circ} \mathrm{W}\end{array}$ & $\begin{array}{l}\sim 6.5 \\
\mathrm{~km}\end{array}$ & $\sim-1.8 \mathrm{~km}$ & $\begin{array}{c}\sim 24^{\circ} / \sim 35^{\circ} / \sim \\
35^{\circ}\end{array}$ & $\begin{array}{c}\text { Poleward/Pol } \\
\text { eward }\end{array}$ & Yes/No & $\begin{array}{c}\sim 1.6 \pm 0.2 \mathrm{Ma}, \\
35-120 \mathrm{~m}, \\
\text { Ejecta }\end{array}$ & ESP_046028_2235 & $\begin{array}{l}\text { B17_016332_2248, } \\
\text { D03_028569_2235 }\end{array}$ & \multirow{6}{*}{ This study } \\
\hline $\begin{array}{l}\text { Unnamed } \\
(\mathrm{NU}-2)\end{array}$ & $\begin{array}{l}44.20^{\circ} \mathrm{N} \\
104.61^{\circ} \mathrm{W}\end{array}$ & $\begin{array}{c}\sim 2.2 \\
\mathrm{~km}\end{array}$ & $\sim 2.65 \mathrm{~km}$ & $\begin{array}{c}\sim 25^{\circ} / \sim 35^{\circ} / \sim \\
39^{\circ}\end{array}$ & $\begin{array}{c}\text { Poleward/Pol } \\
\text { eward }\end{array}$ & Yes/No & $\begin{array}{c}\sim 9.1 \pm 2 \mathrm{Ma}, \\
30-70 \mathrm{~m}, \\
\text { Ejecta }\end{array}$ & ESP_043073_2245 & D13_032405_2244 & \\
\hline $\begin{array}{l}\text { Unnamed } \\
(\mathrm{NU}-3)\end{array}$ & $\begin{array}{l}48.29^{\circ} \mathrm{N} \\
78.16^{\circ} \mathrm{W}\end{array}$ & $\begin{array}{c}\sim 7.0 \\
\mathrm{~km}\end{array}$ & $\begin{array}{c}\sim-0.55 \\
\mathrm{~km}\end{array}$ & $\begin{array}{c}\text { CTX DEM } \\
\text { not } \\
\text { available }\end{array}$ & $\begin{array}{c}\text { Poleward/Pol } \\
\text { eward }\end{array}$ & Yes/No & $\begin{array}{c}\sim 15 \pm 5 \mathrm{Ma}, \\
100-400 \mathrm{~m}, \\
\text { Ejecta }\end{array}$ & ESP_028290_2285 & $\begin{array}{l}\text { P15_007034_2277, } \\
\text { P16_007390_2291 }\end{array}$ & \\
\hline $\begin{array}{l}\text { Unnamed } \\
(\mathrm{NU}-4)\end{array}$ & $\begin{array}{l}44.06^{\circ} \mathrm{N} \\
60.78^{\circ} \mathrm{W}\end{array}$ & $\begin{array}{c}\sim 15.5 \\
\mathrm{~km}\end{array}$ & $\sim-1.6 \mathrm{~km}$ & $\begin{array}{c}\text { CTX DEM } \\
\text { not } \\
\text { available }\end{array}$ & $\begin{array}{l}\text { Poleward- } \\
\text { Equatorward/ } \\
\text { Poleward }\end{array}$ & Yes/No & $\begin{array}{c}\sim 3.8 \pm 0.6 \mathrm{Ma} \\
70-300 \mathrm{~m}, \\
\text { Ejecta }\end{array}$ & ESP_025797_2245 & $\begin{array}{l}\text { B01_010079_2243, } \\
\text { B02_010290_2244, } \\
\text { P22_009723_2251 }\end{array}$ & \\
\hline Gamboa & $\begin{array}{l}40.79^{\circ} \mathrm{N} \\
44.34^{\circ} \mathrm{W}\end{array}$ & $\begin{array}{l}\sim 30.0 \\
\mathrm{~km}\end{array}$ & $\sim-3.2 \mathrm{~km}$ & $\begin{array}{c}\sim 18^{\circ} / \sim 22^{\circ} / \sim \\
29^{\circ}\end{array}$ & $\begin{array}{l}\text { Poleward- } \\
\text { Equatorward/ } \\
\text { Poleward }\end{array}$ & Yes/No & $\begin{array}{c}\sim 270 \pm 60 \mathrm{Ma}, \\
500-1700 \mathrm{~m}, \\
\text { Ejecta }\end{array}$ & ESP_036451_2210 & $\begin{array}{l}\text { B18_016487_2213, } \\
\text { D01_027603_2205, } \\
\text { D03_028236_2205, } \\
\text { D05_02908_2195, } \\
\text { F02_036451_2194, } \\
\text { F04_037242_2195, } \\
\text { F06_038152_2202, } \\
\text { P16_007257_2213 }\end{array}$ & \\
\hline $\begin{array}{l}\text { Unnamed } \\
(\mathrm{NU}-5)\end{array}$ & $\begin{array}{l}53.61^{\circ} \mathrm{N} \\
26.30^{\circ} \mathrm{E}\end{array}$ & $\begin{array}{l}\sim 4.5 \\
\mathrm{~km}\end{array}$ & $\begin{array}{c}\sim-3.83 \\
\mathrm{~km}\end{array}$ & $\begin{array}{c}\text { CTX DEM } \\
\text { not } \\
\text { available }\end{array}$ & $\begin{array}{c}\text { Poleward- } \\
\text { Equatorward/ } \\
\text { Equatorward }\end{array}$ & Yes/No & $\begin{array}{c}\text { Only one } \\
\text { crater is } \\
\text { present on the } \\
\text { ejecta }\end{array}$ & ESP_036501_2340 & $\begin{array}{l}\text { B17_016181_2337, } \\
\text { G23_027231_2335 }\end{array}$ & \\
\hline
\end{tabular}


Craters hosting lobate deposits in the southern hemisphere

\begin{tabular}{|c|c|c|c|c|c|c|c|c|c|}
\hline $\begin{array}{l}\text { Unnamed } \\
\text { (SU-1) }\end{array}$ & $\begin{array}{l}37.17^{\circ} \mathrm{S} \\
169.16^{\circ} \mathrm{W}\end{array}$ & $\begin{array}{c}\sim 18.0 \\
\mathrm{~km}\end{array}$ & $\sim 0.38 \mathrm{~km}$ & $\begin{array}{c}\sim 9^{\circ} / \sim 40^{\circ} / \sim 3 \\
6^{\circ}\end{array}$ & $\begin{array}{c}\text { Poleward/Pol } \\
\text { eward }\end{array}$ & Yes/No & $\begin{array}{c}\sim 3.0 \pm 0.3 \mathrm{Ga} \\
600-2000 \mathrm{~m} \\
\text { Ejecta }\end{array}$ & ESP_036324_1425 & $\begin{array}{l}\text { G16_024575_1441, } \\
\text { P06_003438_1430, } \\
\text { P07_003794_1430, } \\
\text { F22_044368_1428 }\end{array}$ \\
\hline $\begin{array}{l}\text { Unnamed } \\
\text { (SU-2) }\end{array}$ & $\begin{array}{c}42.84^{\circ} \mathrm{S} \\
161.92^{\circ} \mathrm{W}\end{array}$ & $\begin{array}{l}\sim 17.7 \\
0 \mathrm{~km}\end{array}$ & $\sim 1.95 \mathrm{~km}$ & $\begin{array}{c}\sim 13^{\circ} / \sim 25^{\circ} / \sim \\
27^{\circ}\end{array}$ & $\begin{array}{l}\text { Poleward- } \\
\text { Equatorward/ } \\
\text { Poleward }\end{array}$ & Yes/Yes & $\begin{array}{c}33 \pm 10 \mathrm{Ma}, \\
100-300 \mathrm{~m}, \\
\text { small-scale } \\
\text { LDA }\end{array}$ & PSP_007143_1370 & $\begin{array}{c}\text { P12_005719_1381, } \\
\text { B19_016940_1386, } \\
\text { P17_007644_1381 }\end{array}$ \\
\hline $\begin{array}{l}\text { Unnamed } \\
\text { (SU-3) }\end{array}$ & $\begin{array}{c}38.27^{\circ} \mathrm{S} \\
153.23^{\circ} \mathrm{W}\end{array}$ & $\begin{array}{c}\sim 13.2 \\
\mathrm{~km}\end{array}$ & $\sim 2.67 \mathrm{~km}$ & $\begin{array}{c}\sim 13^{\circ} / \sim 25^{\circ} / \sim \\
35^{\circ}\end{array}$ & $\begin{array}{c}\text { Poleward/Pol } \\
\text { eward }\end{array}$ & Yes/Yes & $\begin{array}{c}\sim 2.0 \pm 0.3 \mathrm{Ga} \\
350-1100 \mathrm{~m} \\
\text { Ejecta }\end{array}$ & ESP_038473_1415 & $\begin{array}{l}\text { D08_030482_1414, } \\
\text { D09_030904_1394, } \\
\text { P17_007525_1425 }\end{array}$ \\
\hline Taltal & $\begin{array}{c}39.50^{\circ} \mathrm{S} \\
125.78^{\circ} \mathrm{W}\end{array}$ & $\begin{array}{c}\sim 10.0 \\
\mathrm{~km}\end{array}$ & $\sim 2.44 \mathrm{~km}$ & $\begin{array}{c}\sim 9^{\circ} / \sim 25^{\circ} / \sim 3 \\
2^{\circ}\end{array}$ & $\begin{array}{c}\text { Poleward/Pol } \\
\text { eward }\end{array}$ & Yes/Yes & $\begin{array}{c}490 \pm 100 \\
\mathrm{Ma}, 300- \\
1000 \mathrm{~m} \\
\text { Ejecta }\end{array}$ & ESP_016042_1400 & $\begin{array}{c}\text { B17_016108_1403, } \\
\text { B1_017031_1405, } \\
\text { D02_028002_1402, } \\
\text { P14_006667_1398 }\end{array}$ \\
\hline $\begin{array}{l}\text { Unnamed } \\
\text { (SU-4) }\end{array}$ & $\begin{array}{l}45.84^{\circ} \mathrm{S} \\
99.79^{\circ} \mathrm{W}\end{array}$ & $\begin{array}{c}\sim 33.2 \\
\mathrm{~km}\end{array}$ & $\sim 2.78 \mathrm{~km}$ & $\begin{array}{c}\sim 10^{\circ} / \sim 16^{\circ} / \sim \\
29^{\circ}\end{array}$ & $\begin{array}{l}\text { Poleward- } \\
\text { Equatorward/ } \\
\text { Poleward }\end{array}$ & Yes/Yes & $\begin{array}{l}\text { Ejecta } \\
\text { boundary } \\
\text { cannot be } \\
\text { delineated }\end{array}$ & ESP_030045_1340 & $\begin{array}{c}\text { P18_008090_1344, } \\
\text { 15_007088_1328, } \\
\text { G12_022766_1328, } \\
\text { G11_022344_1328 }\end{array}$ \\
\hline $\begin{array}{l}\text { Unnamed } \\
\text { (SU-5) }\end{array}$ & $\begin{array}{l}45.28^{\circ} \mathrm{S} \\
85.52^{\circ} \mathrm{W}\end{array}$ & $\begin{array}{c}\sim 17.0 \\
\mathrm{~km}\end{array}$ & $\sim 2.73 \mathrm{~km}$ & $\begin{array}{c}\sim 10^{\circ} / \sim 14^{\circ} / \sim \\
21^{\circ}\end{array}$ & $\begin{array}{l}\text { Poleward- } \\
\text { Equatorward/ } \\
\text { Poleward }\end{array}$ & Yes/Yes & $\begin{array}{c}\sim 140 \pm 40 \mathrm{Ma} \\
350-700 \mathrm{~m} \\
\text { Ejecta }\end{array}$ & ESP_047464_1345 & $\begin{array}{l}\text { B11_013944_1346, } \\
\text { P15_006837_1331, } \\
\text { B19_017135_1353 }\end{array}$ \\
\hline Los & $\begin{array}{l}35.08^{\circ} \mathrm{S} \\
76.22^{\circ} \mathrm{W}\end{array}$ & $\begin{array}{c}\sim 7.8 \\
\mathrm{~km}\end{array}$ & $\sim 4.93 \mathrm{~km}$ & $\begin{array}{c}\sim 14^{\circ} / \sim 28^{\circ} \% \\
35^{\circ}\end{array}$ & $\begin{array}{c}\text { Poleward/Pol } \\
\text { eward }\end{array}$ & No/No & $\begin{array}{c}\sim 7.9 \pm 3 \mathrm{Ma} \\
90-250 \mathrm{~m} \\
\text { Ejecta }\end{array}$ & ESP_020774_1445 & $\begin{array}{l}\text { P14_006652_1439, } \\
\text { B18_016594_1441, } \\
\text { B02_010225_1446 }\end{array}$ \\
\hline $\begin{array}{c}\text { Unnamed } \\
\text { (SU-6) }\end{array}$ & $\begin{array}{c}34.65^{\circ} \mathrm{S} \\
6.6^{\circ} \mathrm{W} \\
\end{array}$ & $\begin{array}{c}\sim 3.4 \\
\mathrm{~km}\end{array}$ & $\sim 1.93 \mathrm{~km}$ & $\begin{array}{c}\sim 7^{\circ} / \sim 26^{\circ} / \sim 3 \\
6^{\circ} \\
\end{array}$ & \begin{tabular}{|c|}
$\begin{array}{c}\text { Poleward/Pol } \\
\text { eward }\end{array}$ \\
\end{tabular} & Yes/No & $\begin{array}{c}\text { Ejecta is not } \\
\text { evident }\end{array}$ & PSP_007045_1450 & B17_016130_1451 \\
\hline $\begin{array}{l}\text { Unnamed } \\
\text { (SU-7) }\end{array}$ & $\begin{array}{l}34.45^{\circ} \mathrm{S} \\
129.16^{\circ} \mathrm{E}\end{array}$ & $\begin{array}{c}\sim 13.2 \\
\mathrm{~km}\end{array}$ & $\sim 1.94 \mathrm{~km}$ & $\begin{array}{c}\sim 12^{\circ} / \sim 31^{\circ} \% \\
28^{\circ}\end{array}$ & $\begin{array}{c}\text { Poleward/Pol } \\
\text { eward }\end{array}$ & Yes/Yes & $\begin{array}{c}\sim 28 \pm 8 \mathrm{Ma}, \\
45-120 \mathrm{~m}, \\
\text { small-scale } \\
\text { LDA }\end{array}$ & ESP_013870_1450 & $\begin{array}{l}\text { J02_045755_1437, } \\
\text { G01_018538_1452, } \\
\text { B03_010824_1451 }\end{array}$ \\
\hline
\end{tabular}




\begin{tabular}{|c|c|c|c|c|c|c|c|c|c|c|}
\hline $\begin{array}{l}\text { Unnamed } \\
\text { (SU-8) }\end{array}$ & $\begin{array}{l}33.18^{\circ} \mathrm{S} \\
153.19^{\circ} \mathrm{E}\end{array}$ & $\begin{array}{c}\sim 12.6 \\
\mathrm{~km}\end{array}$ & $\sim 1.5 \mathrm{~km}$ & $\begin{array}{c}\sim 10^{\circ} / \sim 21^{\circ} \% \\
31^{\circ}\end{array}$ & $\begin{array}{c}\text { Poleward/Pol } \\
\text { eward }\end{array}$ & Yes/No & $\begin{array}{c}\text { Ejecta } \\
\text { boundary } \\
\text { cannot be } \\
\text { delineated } \\
\end{array}$ & ESP_016757_1465 & $\begin{array}{l}\text { F07_038343_1465, } \\
\text { P15_006960_1469, } \\
\text { P16_007461_1458 }\end{array}$ & \\
\hline $\begin{array}{l}\text { Unnamed } \\
\text { (SU-9) }\end{array}$ & $\begin{array}{l}36.65^{\circ} \mathrm{S} \\
157.74^{\circ} \mathrm{E}\end{array}$ & $\begin{array}{c}\sim 4.4 \\
\mathrm{~km}\end{array}$ & $\sim 1.07 \mathrm{~km}$ & $\begin{array}{c}\text { CTX DEM } \\
\text { not } \\
\text { available }\end{array}$ & $\begin{array}{c}\text { Poleward/Pol } \\
\text { eward }\end{array}$ & Yes/Yes & $\begin{array}{c}240 \pm 60 \mathrm{Ma}, \\
120-600 \mathrm{~m}, \\
\text { Ejecta }\end{array}$ & ESP_023640_1430 & $\begin{array}{l}\text { B18_016625_1434, } \\
\text { B19_017192_1443. }\end{array}$ & \\
\hline $\begin{array}{l}\text { Unnamed } \\
\text { (SU-10) }\end{array}$ & $\begin{array}{l}36.34^{\circ} \mathrm{S} \\
161.45^{\circ} \mathrm{E}\end{array}$ & $\begin{array}{c}\sim 6.3 \\
\mathrm{~km}\end{array}$ & $\sim 0.6 \mathrm{~km}$ & $\begin{array}{c}\sim 10^{\circ} / \sim 23^{\circ} / \sim \\
30^{\circ}\end{array}$ & $\begin{array}{c}\text { Poleward/Pol } \\
\text { eward }\end{array}$ & Yes/No & $\begin{array}{c}150 \pm 40 \mathrm{Ma}, \\
140-400 \mathrm{~m}, \\
\text { Ejecta } \\
\end{array}$ & ESP_028308_1435 & G14_023864_1442 & \\
\hline $\begin{array}{l}\text { Unnamed } \\
\text { (SU-11) }\end{array}$ & $\begin{array}{l}34.21^{\circ} \mathrm{S} \\
165.58^{\circ} \mathrm{E}\end{array}$ & $\begin{array}{c}\sim 3.1 \\
\mathrm{~km}\end{array}$ & $\sim 1.7 \mathrm{~km}$ & $\begin{array}{c}\sim 19^{\circ} / \sim 32^{\circ} / \sim \\
23^{\circ}\end{array}$ & $\begin{array}{c}\text { Poleward/Pol } \\
\text { eward }\end{array}$ & Yes/Yes & $\begin{array}{c}\sim 250 \pm 60 \mathrm{Ma} \\
120-300 \mathrm{~m}, \\
\text { Ejecta } \\
\end{array}$ & ESP_047125_1455 & F01_036259_1455 & \\
\hline Tarq & $\begin{array}{l}38.10^{\circ} \mathrm{S} \\
171.22^{\circ} \mathrm{E}\end{array}$ & $\begin{array}{c}\sim 35.4 \\
\mathrm{~km}\end{array}$ & $\sim 1.79 \mathrm{~km}$ & $\begin{array}{c}\sim 13^{\circ} / \sim 21^{\circ} \% \\
26^{\circ}\end{array}$ & $\begin{array}{c}\text { Poleward/Pol } \\
\text { eward }\end{array}$ & Yes/Yes & $\begin{array}{c}\sim 30 \pm 10 \mathrm{Ma} \\
\text { 90-250 m, } \\
\text { small-scale } \\
\text { LDA }\end{array}$ & ESP_036839_1420 & $\begin{array}{l}\text { P11_005298_1418, } \\
\text { P16_007434_1416, } \\
\text { P18_007935_1401, } \\
\text { B19_016941_1416 }\end{array}$ & \\
\hline \multicolumn{11}{|c|}{ Previously reported craters hosting lobate deposits in the northern and southern hemispheres } \\
\hline Domoni & $\begin{array}{l}51.38^{\circ} \mathrm{N} \\
125.61^{\circ} \mathrm{W}\end{array}$ & $\begin{array}{c}\sim 13.8 \\
\mathrm{~km}\end{array}$ & $\sim-2.1 \mathrm{~km}$ & $\begin{array}{c}0- \\
10^{\circ} / \mathrm{NA} />3 \\
0^{\circ}\end{array}$ & $\begin{array}{l}\text { Equatorward/ } \\
\text { Equatorward }\end{array}$ & Yes/No & $\begin{array}{l}\sim 19.2 \pm 5.3 \\
\text { Ma, 100-200 } \\
\mathrm{m}, \text { Ejecta }\end{array}$ & ESP_016213_2315 & NA & $\begin{array}{l}\text { Sinha et } \\
\text { al., 2019; } \\
\text { de Haas et } \\
\text { al., 2019b }\end{array}$ \\
\hline $\begin{array}{l}\text { Maricour } \\
\mathrm{t}\end{array}$ & $\begin{array}{l}53.34^{\circ} \mathrm{N} \\
71.17^{\circ} \mathrm{W}\end{array}$ & $\begin{array}{c}\sim 9.9 \\
\mathrm{~km}\end{array}$ & $\begin{array}{c}\sim-3.52 \\
\mathrm{~km}\end{array}$ & $\begin{array}{c}0- \\
14^{\circ} / \mathrm{NA} />3 \\
0^{\circ}\end{array}$ & $\begin{array}{l}\text { Equatorward/ } \\
\text { Equatorward }\end{array}$ & No/No & $\begin{array}{c}\sim 10 \pm 2.8 \mathrm{Ma}, \\
>62 \mathrm{~m}, \text { Ejecta }\end{array}$ & ESP_026061_2335 & NA & $\begin{array}{l}\text { Sinha et } \\
\text { al., } 2019\end{array}$ \\
\hline Galap & $\begin{array}{l}37.66^{\circ} \mathrm{S} \\
167.07^{\circ} \mathrm{W}\end{array}$ & $\begin{array}{c}\sim 6.0 \\
\mathrm{~km}\end{array}$ & $\sim 1.03 \mathrm{~km}$ & $\begin{array}{l}5-10^{\circ} / 15- \\
20^{\circ} / 30-40^{\circ}\end{array}$ & $\begin{array}{c}\text { Poleward/Pol } \\
\text { eward }\end{array}$ & No/No & $\sim 6.5 \mathrm{Ma}$ & PSP_003939_1420 & NA & $\begin{array}{l}\text { de Haas et } \\
\text { al., 2015a }\end{array}$ \\
\hline
\end{tabular}




\begin{tabular}{|c|c|c|c|c|c|c|c|c|c|c|}
\hline Istok & $\begin{array}{l}45.10^{\circ} \mathrm{S}, \\
85.81^{\circ} \mathrm{W}\end{array}$ & $\begin{array}{c}\sim 4.6 \\
\mathrm{~km}\end{array}$ & $\sim 2.57 \mathrm{~km}$ & $\begin{array}{l}8-20^{\circ} / 20- \\
35^{\circ} / 35-45^{\circ}\end{array}$ & $\begin{array}{c}\text { Poleward/Pol } \\
\text { eward }\end{array}$ & No/No & $\begin{array}{l}\sim .19 \pm .04 \mathrm{Ma}, \\
<25 \mathrm{~m}, \text { Ejecta }\end{array}$ & PSP_006837_1345 & NA & $\begin{array}{l}\text { Johnsson } \\
\text { et al., } 2014\end{array}$ \\
\hline Hale & $\begin{array}{l}35.69^{\circ} \mathrm{S} \\
36.35^{\circ} \mathrm{W}\end{array}$ & $\begin{array}{l}\sim 137 . \\
3 \mathrm{~km}\end{array}$ & $\sim 1.6 \mathrm{~km}$ & $\begin{array}{c}\text { Between } 20 \\
\text { and } 30^{\circ}\end{array}$ & $\begin{array}{c}\text { All } \\
\text { directions/eas } \\
\mathrm{t} \text {-facing }\end{array}$ & Yes/No & $\begin{array}{l}\text { Minimum } \\
\text { age: } \sim 1 \mathrm{Ga}\end{array}$ & PSP_006822_1440 & NA & $\begin{array}{c}\text { Reiss et } \\
\text { al., 2009, } \\
2011 ; \\
\text { Jones et } \\
\text { al., } 2011 \\
\end{array}$ \\
\hline Unnamed & $\begin{array}{l}35.16^{\circ} \mathrm{S} \\
165.34^{\circ} \mathrm{E}\end{array}$ & $\begin{array}{c}\sim 6.6 \\
\mathrm{~km}\end{array}$ & $\sim 1.11 \mathrm{~km}$ & $10^{\circ} / 25^{\circ} / \mathrm{NA}$ & $\begin{array}{c}\text { Poleward/Pol } \\
\text { eward }\end{array}$ & Yes/Yes & Not estimated & PSP_003162_1445 & NA & $\begin{array}{l}\text { Lanza et } \\
\text { al., } 2010\end{array}$ \\
\hline
\end{tabular}

$N U$ : North unnamed

SU: South unnamed

NA: Not available 